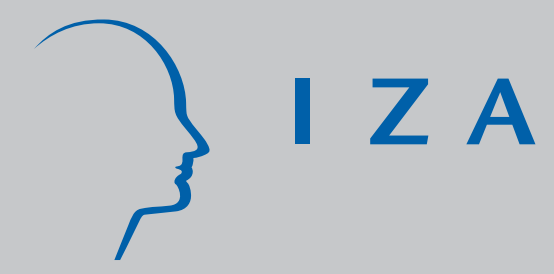

IZA DP No. 3857

Not So Lucky Any More:

CEO Compensation in Financially Distressed Firms

Qiang Kang

Oscar A. Mitnik

November 2008 


\title{
Not So Lucky Any More: CEO Compensation in Financially Distressed Firms
}

\author{
Qiang Kang \\ University of Miami \\ Oscar A. Mitnik \\ University of Miami \\ and IZA \\ Discussion Paper No. 3857 \\ November 2008 \\ IZA \\ P.O. Box 7240 \\ 53072 Bonn \\ Germany \\ Phone: +49-228-3894-0 \\ Fax: +49-228-3894-180 \\ E-mail: iza@iza.org
}

Any opinions expressed here are those of the author(s) and not those of IZA. Research published in this series may include views on policy, but the institute itself takes no institutional policy positions.

The Institute for the Study of Labor (IZA) in Bonn is a local and virtual international research center and a place of communication between science, politics and business. IZA is an independent nonprofit organization supported by Deutsche Post World Net. The center is associated with the University of Bonn and offers a stimulating research environment through its international network, workshops and conferences, data service, project support, research visits and doctoral program. IZA engages in (i) original and internationally competitive research in all fields of labor economics, (ii) development of policy concepts, and (iii) dissemination of research results and concepts to the interested public.

IZA Discussion Papers often represent preliminary work and are circulated to encourage discussion. Citation of such a paper should account for its provisional character. A revised version may be available directly from the author. 
IZA Discussion Paper No. 3857

November 2008

\title{
ABSTRACT \\ Not So Lucky Any More: CEO Compensation in Financially Distressed Firms ${ }^{*}$
}

There is a debate on whether executive pay reflects rent extraction due to "managerial power" or is the result of arms-length bargaining in a principal-agent framework. In this paper we offer a test of the managerial power hypothesis by empirically examining the CEO compensation of U.S. public companies that were ever in financial distress between 1992 and 2005. Using a bias-corrected matching estimator that estimates the causal effects of financial distress, we find that, for the distressed firms, CEO turnover rates increase markedly and their CEOs, both incumbents and successors, experience significant reductions in total compensation. The bulk of the reduction in total compensation derives from the decline in value of stock option grants, which we argue is due to a change in the opportunistic timing of option grants. We define "lucky" grants as those with grant prices below or at the lowest stock price of the grant month, and we find that the proportion of lucky grants for financially distressed firms is higher before insolvency and lower upon and after insolvency, while the proportion for similar but solvent firms remains stable throughout the period. We interpret this evidence as consistent with a decrease in managerial power induced by a tightening in the "outrage" constraint due to the episode of financial distress.

JEL Classification: $\quad$ G30, J33, M52

Keywords: CEO compensation, CEO turnover, financial distress, lucky grants, bias-corrected matching estimators

Corresponding author:

\author{
Qiang Kang \\ Department of Finance \\ University of Miami \\ P.O. Box 248094 \\ Coral Gables, FL 33124-6552 \\ USA \\ E-mail: q.kang@miami.edu
}

\footnotetext{
* We appreciate comments and suggestions from Hulya Eraslan, Yaniv Grinstein, David Kelly, Tom Sanders, and seminar participants at the University of Miami, the University of Texas at Dallas, and the 2007 North American Summer Meeting of the Econometric Society. We thank Lynn M. LoPucki for providing us the Bankruptcy Research Database. We also thank Caitlin Hughes for excellent research assistance. Both authors gratefully acknowledge financial support from the University of Miami. All errors remain our own responsibility.
} 


\section{Introduction}

There is a debate on whether executive pay reflects rent extraction due to "managerial power" or is the result of arms-length bargaining in a principal-agent framework. In this paper we offer a test of the managerial power hypothesis by empirically examining the CEO compensation of U.S. public companies that were ever in financial distress between 1992 and 2005. We use a bias-corrected matching estimator proposed by Abadie and Imbens $(2006,2007)$ to find suitable control firms and to estimate the causal effects of financial distress on CEO compensation and opportunistic timing of option grants.

Executive pay in U.S. public companies has been rising sharply since the 1990s, and the trend has continued and persisted throughout the period of market crashes of the early 2000s and up to the beginning of the current financial/credit crisis. ${ }^{1}$ A prevalent form of compensation is equityrelated incentive pay such as stock grants and stock option grants. The principal-agent model posits that the equity-based compensation aligns managerial interests with shareholder interests and serves as a (partial) remedy to agency problems. ${ }^{2}$ An opposite but increasingly popular view is that the level of executive compensation is excessive and a large portion of what top managers get is not incentive pay but rents extracted by powerful CEOs from dysfunctional boards (see, e.g., Bertrand and Mullainathan, 2001; Bebchuk and Fried, 2003, 2004). The lavish pay to top executives of US firms, particularly to CEOs of those firms near or in bankruptcy, has repeatedly caused outcry from the public. In response, the U.S. Securities and Exchange Commission passed new rules in 2006 requiring companies to more fully and clearly disclose what they are paying to top executives and the total compensation figure. In a similar spirit, the Emergency Economic Stabilization Act of 2008 directs the Treasury to request firms participating in the Troubled Assets Relief Program (TARP) to "meet appropriate standards for executive compensation and corporate

\footnotetext{
${ }^{1}$ For example, Bebchuk and Grinstein (2005) document that, from 1999 to 2003, the five top persons at each of the 1500 largest publicly traded companies in the U.S. cumulatively received $\$ 122$ billion in salary, bonus and stock, compared with $\$ 68$ billion from 1993 to 1997. Moreover, in the 2001-2003 period, top-executive compensation amounted to $9.8 \%$ of the companies' net income, almost double from the $5 \%$ for the 1993-1995 period. A Wall Street Journal analysis, dated on October 31,2008 , shows that financial giants getting federal cash owe over $\$ 40$ billion to executives for past years' pay and pensions as of the end of 2007.

${ }^{2}$ In empirical studies, Jensen and Murphy (1990) claim that observed contracts are fairly insensitive to changes in shareholders wealth; Hall and Liebman (1998) report a much higher pay-performance sensitivity in more recent years. With calibration exercises, both Haubrich (1994) and Aseff and Santos (2005) report that observed pay schedules can be generated by the principal-agent model.
} 
governance" (GPO, 2008, pp. 12). ${ }^{3}$

Our motivation for focusing on CEO compensation in financially distressed firms is as follows. Under the managerial power critique the only effective constraint on executive compensation is the "outrage" constraint given by what compensation level shareholders are willing to tolerate. For firms under financial distress, agency costs are arguably dramatically reduced since sophisticated investors consolidate ownership interests and assert significant control over firms; and managerial power, if any, is much weakened due to a greater degree of scrutiny from stakeholders such as creditors and shareholders, as well as the bankruptcy court judge if Chapter 11 protection is sought. Consequently, the "outrage" constraint should tighten and the CEO compensation practices should change significantly from being financially solvent to financially distressed, with companies seeking to make the compensation package more sensitive to performance. Of course, one could argue that compensation practices change due to other reasons after financial distress (e.g. contract reoptimization in a new business environment). However, any such argument, if true, should be also able to explain the important reduction in opportunistic timing of option grants among distressed firms which we discuss below.

We define as financially distressed the firms that either file for Chapter 11 bankruptcy protection or satisfy both of the following conditions: i) their Ohlson's (1980) O-scores, a commonly used measure of financial health, are in the top quintile of the O-score distribution, and ii) their past three-year cumulative stock returns are in the lowest quintile of the returns distribution, among all publicly traded firms. The evolution of different components of executive compensation of distressed firms over a six-year period (from two years before to three years after financial distress) is then contrasted with that of comparable firms that did not suffer financial distress. We use the Abadie and Imbens' $(2006,2007)$ bias-corrected matching estimator to accomplish this and estimate the causal effects of financial distress on CEO compensation. ${ }^{4}$ This matching method allows us to find

\footnotetext{
${ }^{3}$ The Act defines those standards as a) "limits on compensation that exclude incentives for senior executive officers of a financial institution to take unnecessary and excessive risks..."; b) "a provision for the recovery by the financial institution of any bonus or incentive compensation paid to a senior executive officer based on statements of earnings, gains, or other criteria that are later proven to be materially inaccurate"; and c) "a prohibition on the financial institution making any golden parachute payment to its senior executive officer..." (GPO, 2008, pp. 13).

${ }^{4}$ The Abadie and Imbens' (2006, 2007) estimator has several advantages over other matching estimators like propensity score matching. It is simple to use, it implements a correction for potential biases generated by non-exact matching on (mostly) continuous variables, and it has a well defined asymptotic variance. In addition, this estimator has desirable properties in cases like the one under our study - when the number of treated observations is small relative to the number of control observations, estimating a propensity score model can be problematic.
} 
for our "treated" firms (i.e., the firms that become financially distressed) appropriate "control" firms (i.e., firms that are near-identical in a set of observable characteristics to the treated firms) in a period prior to financial distress during which the treated firms are financially solvent. Using this matching estimator, we find that, for the treated, CEO turnover rates increase markedly and their CEOs, both incumbents and successors, experience significant reductions in total cash compensation and total flow compensation upon and after falling into financial distress. The bulk of the reduction in total compensation derives from the decline in the value of stock option grants which is not explained by changes in stock volatility, stock price, or option maturity. Nor is the reduction in the stock option grants value attributable to the method used to calculate the BlackScholes value.

We also examine the dynamics of managerial opportunistic timing of option grants before and after financial distress. We follow Bebchuk, Grinstein and Peyer's (2006) approach to focus on how grant prices rank within the price distribution of the grant month, and we define "lucky" grants as the ones with grant prices below or at the lowest stock price of the grant month. We find that the proportions of lucky grants for the treated firms are higher before falling into financial distress and lower upon and after becoming distressed, while the proportions of lucky grants for the controls remain stable throughout the same period. Given the well-known comparative statics that the Black-Scholes value of a stock option decreases with respect to the option's exercise price, we argue that the pattern of decreases in lucky option grants for treated firms after financial distress is consistent with the pattern of declines in the Black-Scholes value of stock option grants for those firms. Therefore, we interpret the above evidence as indicative of a decrease in managerial power that is caused by the tightening of the "outrage" constraint due to the episode of financial distress.

Our paper is related to several strands of the literature on executive compensation. First, there is a large and still growing literature on the linkage between CEO compensation and firm performance (see, e.g., Murphy, 1999; Core, Guay and Larcker, 2003). Our paper contributes to this literature by introducing a new method to construct the control group with which we isolate firm-specific shocks from overall market forces. Using the matching method proposed by Abadie and Imbens $(2006,2007)$, we are able to choose at each point of time an appropriate control group which is (statistically) identical to the treatment group (financially distressed firms) in observed 
characteristics before financial distress but is never financially distressed. This is key to properly evaluating the counterfactual compensation policies of financially distressed firms (i.e., what would have been the companies' compensation policies had they not been in financial distress). This focus on counterfactual outcomes, which is not commonly seen in the executive compensation literature, renders our results readily interpreted as reflecting the causal effect of financial distress on CEO compensation practices.

A closely related study is the one by Gilson and Vetsuypens (1993), who examine executive compensation in financially distressed firms during the 1980s. A key difference between our study and theirs is that Gilson and Vetsuypens (1993) just analyze compensation policies of distressed firms before and after financial distress but do not construct a control group to characterize the overall changes in compensation practices that occur during their analysis period; in contrast, we do. Moreover, there have been significant changes in the compensation practices of U.S. public companies, shifting in focus away from bonus-based pay in the 1980s to equity-based pay as of the early 1990s. Thus, our emphasis on the sample period starting in the early 1990s provides a more up-to-date snapshot of the effects of financial distress on CEO compensation and offers an out-of-sample robustness check of their earlier study.

Another related strand in the executive compensation literature is benchmarking or relative performance evaluation; that is, indexing CEO pay to industry or market benchmarks (e.g., Jensen and Murphy, 1990; Gibbons and Murphy, 1990; Aggarwal and Samwick, 1999; Garvey and Milbourn, 2006). In theory, the compensation policy as an incentive mechanism, if working effectively, should pay for good performance and penalize for bad performance. The majority of CEO compensation studies tend to mix the financially healthy and financially distressed firms as well as pool good and bad years for the market. As a result, due to the predominantly strong market years over the period starting from the early 1990s, the findings of such studies might be heavily influenced by pay for good performance and overlook penalty for bad performance, thereby leading to potentially biased inferences. For example, Garvey and Milbourn (2006) report asymmetric benchmarking in compensation so that executives are rewarded for good luck but not penalized for bad luck. Our study, by examining the executive compensation practices in the set of financially distressed firms and by comparing these firms to similar firms that are not financially 
distressed, concentrates on the situations where firms clearly under-perform the market and thus, one would expect that boards would find benchmarking relatively easy to implement. We find clear evidence that new CEOs hired after financial distress are paid significantly less than their predecessors or than CEOs of similar but non-distressed firms, even though the distressed firms with the new leadership on average outperform (at least in terms of stock price increases) the comparable non-distressed firms. Our finding, thus, makes it hard to argue that some sort of benchmarking mechanism is used by the financially distressed firms in designing the pay packages of these newly minted CEOs.

Our paper also relates to the burgeoning literature that studies managerial opportunistic timing of option grants. For example, Lie (2005), Heron and Lie (2006), and Narayanan and Seyhun (2008) all find that firms' abnormal stock returns are negative before executive option grants and positive afterward and attribute the stock return pattern to managerial backdating of option grants. Bebchuk, Grinstein, and Peyer (2006) examine the ranking of a grant price in the distribution of stock prices during the month of the grant and show that lucky grants, i.e., the grants issued at or below the minimum observed stock price in the grant month, provide a useful tool for studying such managerial behavior. Our paper adds to this literature with two findings. First, we find that the proportion of lucky grants decreases after financial distress with respect to both control firms and the pre-distress treated firms. Second, we find evidence on the weakening of such managerial behavior after the enacting of the Sarbanes-Oxley Act of 2002, both for healthy and financially distressed firms, corroborating the finding of Heron and Lie (2006).

Finally, there is a large literature on the relation between CEO turnover and firm performance. Examples, to name a few, include Weisbach (1988), Warner, Watts, and Wruck (1988), Gilson (1989), Huson, Parrino, and Starks (2001), LoPucki (2005), Jenter and Kanaan (2006), and Kaplan and Minton (2006). These studies show that a firm's performance, measured by stock returns or accounting ratios, and with or without filtering out industry or market performance, plays a very important role in affecting CEO turnover rates. Our study concentrates on the role of firm-specific performance in affecting CEO turnover by controlling for the industry and market performance in the procedure of matching the treated with the controls.

The paper proceeds as follows. Section 2 describes the data and the construction of the sample 
under study. Section 3 explains in details the econometric method and the empirical strategy used in the study. Section 4 reports the empirical results on the effect of financial distress on CEO compensation. Section 5 examines the dynamics of managerial opportunistic timing of option grants before and after financial distress. Section 6 concludes.

\section{Data and Sample Construction}

Data for this study comes from several sources. We use executive compensation data from Standard and Poor's (S\&P) ExecuComp database spanning the period from 1992 to 2005. The database reports annual compensation flows as well as information related to changes in the value of stock and stock option holdings for the five highest paid executives, including the CEO, for each firm appearing in the S\&P500 Index, S\&P MidCap 400 Index, and the S\&P SmallCap 600 Index. Firms' annual accounting data comes from S\&P's Compustat database. We obtain stock return data from the Center for Research in Security Prices (CRSP) Monthly Stock File. We take bankruptcy filing information from Professor Lynn LoPucki's Bankruptcy Research Database (BRD). Throughout our empirical analysis, we measure all monetary terms in 2005 constant dollars, and we adjust nominal stock returns by the Consumer Price Index (CPI) from the Bureau of Labor Statistics to obtain real returns.

\subsection{Variables}

Three sets of variables are key to this empirical study. The first set is the measure of financial distress with which we classify firms into financially distressed or healthy. The financially distressed firms in our sample consist of two (in some cases overlapping) groups. One group is formed by the firms that have filed for Chapter 11 bankruptcy and are covered in the BRD. The other group of financially distressed firms are identified based on a combination of the past three-year cumulative stock returns and Ohlson's (1980) O-scores. ${ }^{5}$ Specifically, at each year-end and from the universe

\footnotetext{
${ }^{5}$ To calculate the past three-year cumulative stock returns, we require at least 18 months of valid data within the three-year period. Ohlson's (1980) O-score is a widely-used measure for a firm's financial status, and it is obtained from a probabilistic prediction of bankruptcy with a set of financial ratios including the logarithm value of total assets, the ratio of total liabilities to total assets, the ratio of working capital to total assets, the ratio of current liabilities to current assets, the ratio of net income to total assets, the ratio of funds from operation to total liabilities, the growth rate in net income, the dummy for total liabilities exceeding total assets, and the dummy for negative net income for the last two years. Typically, the higher is the value of the O-score, the more likely is the firm to go bankrupt.
} 
of all Compustat firms having non-missing information for both the O-scores and the prior threeyear stock returns, we rank firms into percentiles based separately on their O-scores and three-year cumulative returns; we exclude the financial sector firms from the rankings. We then classify those firms as financially distressed if the following two conditions are satisfied simultaneously: their O-scores are in the top quintile of the O-score distribution and their past three-year cumulative returns are in the bottom quintile of the cumulative return distribution. ${ }^{6}$

The second set of key variables is comprised of the outcome variables, i.e., different components of executive compensation. We focus on the compensation packages of CEOs who arguably make most of the major corporate decisions and exert the greatest influence on firms among the firms' senior executives. CEO compensation consists of several components. Total current compensation $(T C C)$ is the sum of salary and bonus. Total direct compensation 1 (TDC1) is the sum of total current compensation, the value of restricted stock grants (RSTGRNT), the Black-Scholes value of stock option grants $(B L K V)$, and others. The "others" item includes other annual short-term compensation, payouts from long-term incentive plans, and all other long-term compensation. Besides $T D C 1$, we use $T D C 2$ as another measure of the total flow compensation to a CEO within one fiscal year, which is the sum of TCC, RSTGRNT, value realized from option exercises $(E X E R)$, and others. For equity-based compensation, we calculate two measures of CEO ownership: the stock ownership excluding option grants $(S H O W N)$, which is the total number of stock shares (options excluded) held by a CEO scaled by the total number of firm shares outstanding, and the stock ownership represented by option grants $(O P G R N T)$, which is the total number of stock shares represented by options granted to a CEO divided by the total number of firm shares outstanding.

The third set of key variables consists of the covariates we use to directly match distressed firms with control firms. To identify the impact of financial distress on CEO compensation we resort to the Abadie and Imbens' (2006, 2007) matching estimator. (See Section 3 for a detailed discussion about the estimator.) The matching covariates include O-score, past three-year cumulative stock return, firm size measured by the log value of market capitalization, leverage measured by debt-to-

\footnotetext{
${ }^{6}$ We also identify financially distressed firms with alternative combinations of those percentile cutoffs such as the top decile on $\mathrm{O}$-scores and the bottom decile on cumulative stock returns; the results under those alternative classifications are qualitatively similar and are available upon request.
} 
asset ratio, one O-score-based dummy, one cumulative-return-based dummy, one size-based dummy, industry, fiscal year, total current compensation, and total direct compensation. All the covariates are defined in the base year, that is, three years prior to the episode of financial distress. We use raw values of the O-score, the past three-year cumulative stock return, and firm size as measures of a firm's financial health. To better characterize our criteria of classifying firms into distressed and solvent, we also include dummies based on the three raw measures: the O-score-based dummy that is equal to one if a firms's O-score is at or above the top quintile of all firms in Compustat and zero otherwise; the cumulative-return-based dummy that is equal to one if a firms's past three-year cumulative return is at or below the bottom quintile of all firms in Compustat and zero otherwise; and the size-based dummy that is equal to one if a firm's market capitalization is at or above the top 70 percentile of all firms in Compustat and zero otherwise. Moreover, it is well documented in the literature that leverage, industry and year are also important determinants of a firm's financial status. We adopt Fama and French's 5-industry definition based on the 4-digit SIC code and create five industry dummies on which we also match. We use fiscal year dummies to characterize the year effect on a firm's financial health. Finally, because we try to identify through matching the control firms that are similar to the treated firms in as many aspects as possible, we also match on the level and structure of CEO compensation packages; we thus include both total current compensation $(T C C)$ and total direct compensation $(T D C 1)$ as matching covariates.

\subsection{Sample construction}

Due to the data coverage of ExecuComp, our sample starts in 1992 and we include all compensation information up to 2005. Moreover, because we are interested in the evolution of CEO compensation practices over time, we choose an analysis window of two years before distress through three years after distress, a total of six years. Including the two pre-distress years allows us to capture the case where timing might be off if our definition of financial distress does not identify the timing of distress perfectly. Accordingly, we match the treated group to similar firms based on the matching covariates in the year immediately prior to the analysis window, i.e, three years before a firm becomes financially distressed. As a result, we focus our analysis on the firms that we identify as financially distressed between 1995 and 2002, and we drop the firms that were ever distressed before 1995 or after 2002 . 
The treatment in our study is defined as the "event" that a firm falls into financial distress. We use the term financial distress broadly to include both bankruptcies and our measure of financial distress as described above. Most firms are in either of those two groups, but some would qualify as financially distressed under both definitions. Because a firm can become financially distressed more than once over time, we restrict the treatment to be the first time that a firm becomes financially distressed (by either definition). In only a few cases we include a second spell in distress for the same firm, if at least seven years have passed since the end of the first distress spell. In order to maintain a clean potential pool of controls for the treated group, we drop from the pool of potential controls any solvent firm which has ever been financially distressed before.

Further, we apply the following two criteria to select firms into our analysis sample: 1) Firms do not have missing information for either the matching covariates or compensation variables in the matching year(i.e, three years before the treatment); and 2) firms have at most one missing variable in all compensation variables in the pre-treatment window (i.e., from two years before treatment to the treatment year) and at most one missing variable in all compensation variables in the posttreatment window (i.e., from one year after the treatment to three years after the treatment). As a result, our analysis sample contains 99 firms that were ever in financial distress and 1,205 firms that have never been in financial distress during the 1995-2002 period. ${ }^{7}$

Table 1 breaks down the distribution of the treated group and the pool of potential controls of the analysis sample across years. ${ }^{8}$ Note that each of the potential control firms is assigned to a particular year, which is done to avoid introducing serial correlation issues in the estimation of the standard errors of our matching estimators. We defer to Section 3.2 the detailed explanation of how we determine the year for each potential control firm, after we present the matching estimator in Section 3.1.

\footnotetext{
${ }^{7}$ Although we find 43 firms that file for Chapter 11 protection (e.g. appear in the BRD) and also appear in ExecuComp in the 1995-2002 period, only 10 of those firms have enough valid information to be included in our analysis sample.

${ }^{8}$ For several of the compensation variables we observe outliers that could potentially affect the results. We thus drop from our analysis the observations with the lowest and highest values for every outcome variable and for the treated and the controls separately. This is why the sample sizes of the treated and controls appear as being at most 97 and 1,203 in Table 1. We apply the same "trimming" rule when calculating the matching estimators. Using different "trimming" rules, we obtain similar results which are available upon request.
} 


\subsection{Descriptive statistics}

Table 2 reports the average CEO turnover rates in various subperiods for the treated and potential controls firms. For notational convenience, we refer to the year of the episode of financial distress as "time 0" and express all other years relative to time 0 throughout the paper. For example, the window $[-1,+1]$ corresponds to the subperiod from one year before to one year after financial distress. Table 2 shows that the average turnover rate is significantly higher in the treated group than in the potential controls. For example, in the $[-1,+1]$ subperiod the average CEO turnover rate is $52 \%$ for the treated group and $33 \%$ for the potential controls. The average CEO turnover rates for the treated group increase to $63 \%$ and $69 \%$ for the two subperiods $[-1,+2]$ and $[-1,+3]$, respectively. In contrast, the corresponding CEO turnover rate for the potential controls are $41 \%$ and $48 \%$, respectively. Clearly, for financially distressed firms, most of the CEO turnover occurs in the year of distress (time 0$)$ and in the following year (time +1$)$.

Table 3 presents the descriptive statistics for the outcome variables over time for the treatment and potential controls groups. (Similar descriptive statistics for subsamples, defined by whether firms experience CEO turnover or not, are available upon request.) A few interesting patterns stand out. First, the level of the total flow compensation TDC1 is mainly determined by the Black-Scholes value of stock option grants $B L K V$, while the total current compensation $T C C$ and the value of restricted stock grants $R S T G R N T$ account for a much smaller share of this total flow compensation. Second, both the Black-Scholes value of stock option grants and value realized from options exercised vary widely over time; there are much smaller fluctuations in bonus, the value of restricted stock grants, and stock ownership through option grants; and the salary portion of compensation is quite stable, consistent with the notion that it is more or less a fixed pay. As a result, we can infer that the time variations in $T D C 1$ and, to some extent, $T D C 2$ are mainly caused by the time variations in $B L K V$ and $E X E R$, respectively.

We observe other interesting patterns by comparing the descriptive statistics of the treated group with those of the potential controls. While $B L K V$ of the treated group shows a generally decreasing trend from the pre-treatment years to the post-treatment years, the potential controls exhibit an opposite trend of increase over time; a similar pattern is followed by the compensation measures $T D C 1, T D C 2$, and $R S T G R N T$. In addition, note that except for salary and stock 
ownership through option grants, each of the compensation components for the treated group is significantly smaller than the corresponding compensation components for the potential controls in almost all of the post-treatment years.

\section{$3 \quad$ Empirical Strategy}

The main objective of this paper is to examine the impact of a firm falling into financial distress on the firm's CEO compensation practices. We consider financial distress as a treatment, and following the terminology of the program evaluation literature, we construct a control group to estimate the causal effect of financial distress on CEO compensation. The basic intuition is that the control group allows us to determine the counterfactual, i.e., what the compensation packages of the distressed firms would have been if they had not suffered financial distress. In a standard regression framework, all the firms that did not suffer financial distress would form the control group, but using such a control group could lead to biased inference, as shown in the program evaluation literature. Therefore, an appropriate way is to find non-distressed firms that are statistically identical (or at least as close as possible) to the treated firms in observable characteristics and compensation policies before the episode of financial distress and to select solely those firms as controls. Below we explain the details of our approach.

\subsection{Matching estimators}

There are different methods that can be used to implement our approach. In this paper we use the Abadie and Imbens' (2006, 2007, AI hereafter) matching estimators which match directly on covariates (both continuous and discrete). These estimators have several advantages compared to other common methods like propensity score matching. Not only are they simple to use, but they also implement a correction for potential biases generated by non-exact matching on (mostly) continuous variables and they have a well defined asymptotic variance. ${ }^{9}$ Most importantly, they are well suited and have desirable properties in a case like the one under study — when the number of treated observations is small relative to the number of control observations, estimating

\footnotetext{
${ }^{9}$ Being able to analytically calculate the asymptotic variance saves computing time with respect to estimating it by bootstrapping. Moreover, Abadie and Imbens (forthcoming) show that bootstrapping fails for matching estimators.
} 
a propensity score (i.e., probability of treatment) model with the usual logit or probit method can generate undesirable results.

Following the usual notation in the program evaluation literature, let $Y_{i}(0)$ and $Y_{i}(1)$ denote the potential outcomes of unit $i$ under control and treatment status respectively, for $i=1, . ., N$. For each unit $i$ we observe the treatment received $T_{i}$ for $T_{i} \in\{0,1\}$ and the outcome for each treatment, $Y_{i}=Y_{i}(0)$ if $T_{i}=0$ and $Y_{i}=Y_{i}(1)$ if $T_{i}=1$, as well as a vector of pre-treatment variables or covariates $X_{i}$. There are $N_{0}$ control units and $N_{1}$ treated units, $N=N_{0}+N_{1}$. We are interested in estimating the Average Treatment Effect for the Treated (ATT)

$$
\tau^{t}=E\left[Y_{i}(1)-Y_{i}(0) \mid T i=1\right]
$$

The main identifying assumption necessary to estimate the above ATT is known as unconfoundedness or the Conditional Independence Assumption (CIA). It assumes that $\left(Y_{i}(1), Y_{i}(0)\right) \perp T_{i} \mid X_{i}$. This implies that after controlling for observable characteristics the potential outcomes are independent of the treatment status. Actually, following Abadie and Imbens (2006, 2007) only a weaker version of the CIA is needed for estimating the ATT by matching; we only need $Y_{i}(0) \perp T_{i} \mid X_{i}$, that is, $T_{i}$ is independent of $Y_{i}(0)$ conditional on $X_{i} \cdot{ }^{10}$ The intuition is that, after we control for all potential confounders $X_{i}$ we can assume that the treatment is as good as a randomized treatment.

Abadie and Imbens $(2006,2007)$ consider the case of matching with replacement, allowing each unit to be used as a match more than once. This has the advantage of improving the average match quality with respect to the case of matching without replacement, but implies that special attention must be paid to the number of times a unit is used as a match. Following AI's notation, let $j_{m}(i)$ be the index of the $m$-th match to unit $i$ (i.e. $j_{m}(i)$ is the $m$-th closest unit to unit $i$ in terms of the covariate values, measured by the Euclidean distance between the two vectors). Let $\mathcal{J}_{M}(i)=\left\{j_{i}(1), \ldots, j_{M}(i)\right\}$ denote the set of indices for the first $M$ matches for unit $i$, and let $K_{M}(i)$ denote the number of times unit $i$ is used as a match if $M$ matches are done per unit, $K_{M}(i)=\Sigma_{l=1}^{N} 1\left\{i \in \mathcal{J}_{M}(l)\right\}$, where $1\{\cdot\}$ is the indicator function. Now, for $i=1, \ldots, N$ define the

\footnotetext{
${ }^{10}$ In addition to the CIA, we need to satisfy an overlap condition and other regularity conditions. See Abadie and Imbens (2006, 2007) for details.
} 
imputed potential outcome under the control status as

$$
\hat{Y}_{i}(0)=\left\{\begin{array}{lr}
Y_{i} & \text { if } T_{i}=0 \\
\frac{1}{M} \sum_{j \in \mathcal{J}_{M}(i)} Y_{j} & \text { if } T_{i}=1 .
\end{array}\right.
$$

Then, AI write the matching estimator for the ATT that uses $M$ matches per unit with replacement as

$$
\begin{aligned}
\hat{\tau}_{M}^{m, t} & =\frac{1}{N_{1}} \sum_{j \in \mathcal{J}_{M}(i)}\left(Y_{i}-\hat{Y}_{i}(0)\right) \\
& =\frac{1}{N_{1}} \sum_{T_{i}=1}\left(T_{i}-\left(1-T_{i}\right) \frac{K_{M}(i)}{M}\right) Y_{i}
\end{aligned}
$$

This is called the simple matching estimator. Abadie and Imbens (2006) show that this estimator is not $\mathrm{N}^{1 / 2}$-consistent in general, because it includes a conditional bias term that may be of order larger than $\mathrm{N}^{-1 / 2}$, unless the matching variables include at most one continuous variable. An attractive property of this estimator is that the estimator for the asymptotic variance proposed by AI does not rely on bootstrapping (contrary to other matching methods).

Abadie and Imbens (2007) also propose a bias-corrected matching estimator where the difference within the matches is regression-adjusted for the difference in covariate values:

$$
\tilde{Y}_{i}(0)= \begin{cases}Y_{i} & \text { if } T_{i}=0 \\ \frac{1}{M} \sum_{j \in \mathcal{J}_{M}(i)}\left(Y_{j}+\hat{\mu}_{0}\left(X_{i}\right)-\hat{\mu}_{0}\left(X_{j}\right)\right. & \text { if } T_{i}=1 .\end{cases}
$$

where $\hat{\mu}_{0}$ is a consistent estimator of $\mu_{0}=E[Y(t) \mid X=x]$. The bias-corrected matching estimator that uses $M$ matches per unit with replacement is then

$$
\hat{\tau}_{M}^{b c m, t}=\frac{1}{N_{1}} \sum_{j \in \mathcal{J}_{M}(i)}\left(Y_{i}-\tilde{Y}_{i}(0)\right) .
$$

Contrary to the simple matching estimator, Abadie and Imbens (2007) show that this biascorrected matching estimator is $N^{1 / 2}$-consistent and asymptotically normal. In this paper we estimate both the simple matching estimator and the bias-corrected matching estimator, and 
the latter is our preferred estimator. We carry out such estimations using the Stata command "nnmatch" which is discussed in details in Abadie et al. (2004).

\subsection{Issues in estimating the ATT of financial distress on CEO compensation}

One difficulty in estimating the ATT of financial distress on CEO compensation is that we have properly defined the treated and control groups (firms that ever go into financial distress in the period versus firms that never do), but the timing of treatment (fiscal year in which the firm goes into distress) is only properly defined for the treated firms. This is relevant because the standard practice in estimating treatment effects is to define as time $t=0$ the time of the treatment and express all variables (both outcomes and covariates) with respect to time 0 . The matching should be performed on covariates that are not affected by the treatment (i.e. before $t=0$ ) and possibly include pre-treatment outcomes, while outcomes are the values of the post-treatment variables of interest.

In our case though, it is not properly defined what $\mathrm{t}=0$ means for non-distressed firms because we observe most of the firms every year and in none of those years they go into financial distress. One solution to this problem would be to generate a dataset of "potential controls" in which any firm with valid information is "recentered" at time $t=0$ every period and is potentially included several times. ${ }^{11}$ For example, if firm XYZ appears in all the years from 1995 to 2002, then XYZ would be included in the dataset eight times (once every year); and for each instance we could center each particular fiscal year as time $t=0$. In this way XYZ would appear once in the dataset where $\mathrm{t}=0$ corresponds to the year $1995, \mathrm{t}=-1$ to 1994 and $\mathrm{t}=+1$ to 1996 ; and appear at another time where $\mathrm{t}=0$ corresponds to the year $1996, \mathrm{t}=-1$ to 1995 and $\mathrm{t}=+1$ to 1997 ; etc.

However, a problem with that solution is that it would incorrectly assume that each instance (in different years) of the firm XYZ is independent of each other. The matching method deals effectively with sampling with replacement within the same period but cannot deal with the potential serial correlation introduced by the above exposed approach. To avoid that problem, we use each potential control firm only once. This means that we use firm XYZ as a potential control by considering $\mathrm{t}=0$,

\footnotetext{
${ }^{11}$ Because the matching estimator consists of selecting the best possible $M$ matches (with replacement) per treated firm, some of these firms may never be good enough matches to be actually used as controls in the matching estimator. This is why we call these firms "potential controls".
} 
say, either as 1995 or as 1996, but not both. One way to implement this restriction would be just randomly selecting the year for which firms will be potential controls; such randomization avoids the serial correlation problem but might not use the available information efficiently.

An alternative and much better way is to assign each of these non-distressed firms to the year in which they could potentially be most useful. That is, we want to find among all possible years in which a non-distressed firm could be used as a control or the best match for a treated firm. To implement this idea, we essentially apply our matching estimator twice. Specifically, in the first round, for each year we take all the financially distressed firms in that particular year, match them against all the non-distressed firms, and calculate the Euclidean distance between each treated firm and each non-distressed firm. Then for each non-distressed firm, we rank these distances across all possible years and pick out the treated firm with which the particular non-distressed firm has the smallest distance. Thus, the year in which that particular firm went into distress becomes the best possible year in which we can use the non-distressed firm as a control, across all possible years in which it could have been used as a control. Repeating this procedure for each non-distressed firm we essentially find the year in which each non-distressed firm could potentially be the best possible match of the treated, and we use each non-distressed firm as potential control in that year only. This is how we assign the potential controls to different years as presented in Table 1. Note that even in this situation all these chosen non-distressed firms are still potential controls (i.e., some of the non-distressed firms will never be used in the matching estimation). In the second round, given that we have assigned each non-distressed firm to one and only one year, we pool together all the years and use the matching estimator again to find the best $M$ matches for each treated firm in each year. We set the number of matches to $M=4$, which Abadie and Imbens' (2007) simulation analysis shows to minimize the root of the mean squared error. ${ }^{12}$

Also note that $\mathrm{t}=0$ could potentially refer to different calendar periods for the treated and the controls in a matched pair. For example, a control firm in a "good" year for the overall market could be matched with a treated firm which goes into distress in a "bad" year for the market. To avoid this problem, we include the fiscal years of the treatment as matching covariates to force that the comparisons of the treated firms and the control firms are done within the same calendar

\footnotetext{
${ }^{12}$ In our estimations we also tried alternative values of $M$, from one to four, and the results are similar and are available upon request.
} 
period.

A second issue of importance is that our criteria for identifying a financially distressed firm includes the cumulative stock returns over the past three years. It means that whenever we set time $t=0$ for a treated firm, the determination of $t=0$ is actually based (partly) on the stock performance not only in $t=0$, but also in $t=-1$ and $t=-2$. As explained in the previous section, this potentially "contaminates" all the pre-treatment variables in $\mathrm{t}=-1$ and $\mathrm{t}=-2$; it may not satisfy the CIA condition that outcomes are not affected by the treatment because at least stock returns in each of these two pre-treatment years are mechanically low for firms going into distress at $\mathrm{t}=0$. This can further affect other variables including those related to CEO compensation. Therefore, we perform the matching on covariates measured at $\mathrm{t}=-3$, which should not be affected by the determination of the treatment status.

\subsection{Assessment of matching quality}

Before discussing empirical results we assess the quality of matching which is critical to the success of identifying the treatment effect. Table 4 presents the summary statistics of the matching covariates for the treated and the (potential) controls before and after the matching.

The first panel of the table shows the mean and standard deviation of the matching covariates for the 99 treated firms, while the second panel shows the same information for the pool of 1,205 potential control firms. The third panel calculates the difference and standard error in each matching covariate between the treated group and the potential controls. It appears that the two sets of firms are quite different in several matching covariates, particularly the year and industry distribution, firm leverage, O-score and the past three-year cumulative stock return. Specifically, relative to the pool of potential controls, $8 \%$ more of the treated firms are concentrated in the fiscal year 1998 but $16 \%$ less of the treated firms are concentrated in the year 2001; $11 \%$ less of the treated firms belong to the industry with $\mathrm{SIC}=2$, but $12 \%$ more of the treated firms are in the industry with $\mathrm{SIC}=3$; the average O-scores of the treated firms are significantly higher and $7 \%$ more of the treated are in the top quintile of the O-score distribution. More problematically, the average past three-year cumulative return of the treated firms exceeds that of the potential controls by $24 \%$ and the gap is significantly different from zero. 
The fourth panel of Table 4 shows the mean and standard error of the within-match differences in the covariates between the treated firms and the actually used controls when we apply the matching estimator. Analyzing the within-match difference allows us to evaluate the quality of the matching and shows how the matching improves balancing of the covariates between the treated and controls groups. Note that, because we match each treated firm with four controls $(M=4)$, the number of observations represents the number of within-match differences used in the calculations and, of course, equals the number of treated firms multiplied by four.

Clearly, once the matching procedure selects the best controls for the treated firms, the two groups are much more similar to each other. The matching succeeds for all the dummy variables. In particular, the year and industry classifications are now balanced. The balancing of covariates is very good for the continuous variables too, although not perfect. The difference in the O-scores between the two groups is cut in half, decreasing from $6 \%$ to $3 \%$, but remains statistically significant after matching. The cumulative stock return shows the largest improvement, with the difference between the treated and the actual controls dropping sharply from a significant $24 \%$ gap to a minimal and insignificant $4 \%$ gap. One exception is market capitalization in that the difference in firm size between the treated firms and the controls becomes significant after the matching. However, the difference in firm size does decrease from 0.25 to 0.22 with the matching, but the significant reduction in the standard error of the difference, shrinking from 0.15 before the matching to 0.08 after the matching explains the increase in statistical significance. This suggests that firms that go into financial distress are in average smaller than firms that do not, and we have a hard time finding firms of equivalent size as controls.

To sum up, the overall quality of the matching appears to be quite good and the matching works well in balancing differences in observed characteristics between the financially distressed firms and the comparable non-distressed firms. Note that we even match on the level and composition of CEO compensation at $\mathrm{t}=-3$, which implies that the treatment and control firms are similar not only in their characteristics and financial situations but also in their compensation policies. Below we proceed to use the matching estimator to estimate the causal effects of financial distress on CEO compensation. 


\section{The Effects of Financial Distress on CEO Compensation}

The outcomes of interest are the compensation components that are summarized in Table 3. For each outcome variable we estimate the Average Treatment on the Treated (ATT) effect over the period from two years before the firm goes into financial distress $(t=-2)$ up to three years after $(\mathrm{t}=+3)$. There are two reasons to include the pre-treatment years in the window of analysis. On one hand, the event year $(t=0)$, in which the firm goes into financial distress, is determined based on our method as explained in Section 3, so one may question the precision of the timing. By examining whether there is any treatment effect before $\mathrm{t}=0$, we also implicitly check whether the timing of our treatment variable is correct or not. Second, and more importantly, estimating the ATT on pre-treatment outcomes provides an indirect test on the feasibility of the Conditional Independence Assumption (CIA). The CIA is not testable, but as first noted in Heckman and Hotz (1989), one can estimate the treatment effect over a period during which there should be no treatment effect and test whether that estimated effect is zero. If the hypothesis of zero treatment effect is rejected, then it is much harder to argue that the CIA holds. Therefore, for the sake of our study, we should expect the ATT on the pre-treatment outcomes to be zero.

Another concern regarding the CIA is that there might exist unobserved heterogeneity that differs across the treated and the actual controls, even after matching. The matching method is designed to deal with differences in observed covariates, but it is also possible to control for certain types of unobserved heterogeneity. If the unobserved heterogeneity generates systematic differences in CEO compensation and the heterogeneity is fixed over time (say, the firm's location, the type of products the firm sells, the characteristics of the industry the firm belongs to, etc.), then we can subtract from each outcome variable the value of the same variable in a pre-treatment base year such that this invariant unobserved heterogeneity is removed. This differences-in-differences $(D I D)$ type of estimator is preferred to the level estimator because the $D I D$ method removes any time-invariant heterogeneity not taken care of by the matching on observable characteristics.

\subsection{Results for all treated firms}

Table 5 presents the treatment effects on CEO compensation for all the treated firms using the DID method. (For brevity, we do not report the ATT effects based on the level estimators and the results 
are available upon request.) Nine components of CEO compensation are considered, including cash compensation (Salary, Bonus, and TCC which is the sum of both); stock-based compensation (the Black-Scholes value of options granted, $B L K V$, and the value of restricted stock granted, RSTGRNT); the total flow compensation including the aforementioned components, $T D C 1$; stock compensation based on exercising previously granted options, EXER; another measure of the total flow compensation incorporating the value realized from options exercised, TDC2; and stock ownership through option grants, OPGRNT, which is defined as the log value of the ratio of the number of shares represented by option grants to the firm's total shares outstanding. We implement the $D I D$ version of the matching estimator by setting $\mathrm{t}=-3$ as the base period.

Panels $\mathrm{A}$ and $\mathrm{B}$ of Table 5 present the results from estimating a simple matching estimator and a bias-corrected matching estimator, respectively, with robust standard errors reported in parentheses. As expected, given the quality of the matching, the treatment effects identified by the simple matching estimators and the bias-corrected matching estimators do not differ much qualitatively. Still, because the bias-corrected estimator deals with biases caused by non-perfect matching on covariates, we prefer the treatment effects estimated by the bias-corrected matching estimation and concentrate our analysis on those results (in any case the results from the simple matching estimation are qualitatively the same).

The first thing to notice in Table 5 is that the treatment effects for the nine outcome variables in the $\mathrm{t}=-2$ period are virtually zero with the only exceptions being $E X E R$ and $T D C 2$ (which is driven by the difference in $E X E R)$. It shows that the compensation policies of the treated and control groups are essentially the same up to two years before financial distress, although CEOs of soon-to-be distressed firms exercise more of their options owned. In the year before distress (i.e., $\mathrm{t}=-$ 1), we see that some components of CEO compensation, namely, Bonus, TCC, and RSTGRNT, become significantly different between the treated and control groups, which seems to indicate that the effects of financial distress appear earlier than the episode of the distress. We expect these types of results, in particular for $\mathrm{t}=-1$, given that our criteria for determining the first period of financial distress is somewhat arbitrary. Overall, the evidence that the majority of the CEO compensation components are not significantly different between the treated and the controls in the pre-treatment years, together with the evidence on the quality of matching as presented in Table 4, suggest that 
we have done reasonably well in defining the treatment status and the timing of financial distress. ${ }^{13}$

Table 5 shows that the CEO's total cash compensation, TCC, of the distressed firms decreases after $\mathrm{t}=0$ in the order of $\$ 400$ thousands per year. This is a large effect in percentage terms with respect to the total cash compensation in either the pre-treatment years or the treatment year (in the respective order of $30 \%$ to $45 \%$, see Table 3). Notably, the change in $T C C$ is explained almost entirely by an increase in the gap in bonus between the treated and control firms after the treatment year. Moreover, Table 5 clearly illustrates, relative to the cash compensation, a much larger negative effect on stock-based compensation, particularly the Black-Scholes value of option grants, $B L K V$. The value of $B L K V$ drops by $\$ 2.3$ million immediately in the distress year $(\mathrm{t}=0)$, and continues to decline by $\$ 5$ million in the first year after distress $(t=+1)$, followed by a reduction of $\$ 2.7$ million in the second year after distress $(\mathrm{t}=+2)$ and a statistically insignificant decrease in the third year after financial distress $(\mathrm{t}=+3)$. The value of stock grants, RSTGRNT, declines slightly in the treatment year and the post-treatment period, but the magnitude is much smaller and the treatment effect on $R S T G R N T$ becomes trivial compared to the effect on $B L K V$. As a result, the effect on the total flow compensation to CEOs, $T D C 1$, is overwhelmingly driven by the effect on $B L K V$. The value of $T D C 1$ drops by $\$ 3.2$ million immediately in the year of financial distress $(\mathrm{t}=0)$, and continues to decrease by $\$ 5.8$ million in the first year after distress $(\mathrm{t}=+1)$, followed by a decline of $\$ 3.5$ million in the second year after distress $(t=+2)$ and a statistically insignificant decline of $\$ 1.3$ million in the third year after financial distress $(t=+3)$.

Table 5 also shows that the value realized from exercising options, EXER, decreases by about $\$ 2$ million per year after financial distress. The treatment effect on $E X E R$ is not surprising as the stock prices of the distressed firms decline significantly after falling into financial distress, thereby reducing the value of previously-granted stock options. Consequently, the treatment effect on the alternative measure of total flow compensation to CEOs, $T D C 2$, which is driven by the negative treatment effect on $E X E R$, shows a similar pattern as EXER. Table 5 also evidences the impact of financial distress on the practices of option grants in that the stock ownership through stock

\footnotetext{
${ }^{13}$ The results bode well for the Conditional Independence Assumption. As mentioned before, the CIA is not testable. But, if before the treatment we can show that the outcome variables are not statistically different across the treatment and control groups, it is at least easier to claim that it holds. Our results show that firms match well in $\mathrm{t}=-3$, including on compensation variables. And, even in $\mathrm{t}=-2$, there are no important differences in $\mathrm{CEO}$ compensation between the two groups (except for the ones generated by $E X E R$ ).
} 
option grants increases in the post-treatment years. That is, the companies under financial distress appear to grant more options as CEO compensation in lieu of cash compensation, probably because these firms lack cash/liquidity due to the distress.

In summary, the results show that financial distress significantly impacts the level and structure of CEO compensation and that the most significant effect is on the Black-Scholes value of option grants, $B L K V$. As a consequence of a decrease in $B L K V$ for the treated firms and an increase in $B L K V$ for the control firms, the effect of financial distress on stock-based compensation is large. The time-series of $B L K V$ for the treated firms exhibits a sharp jump in $\mathrm{t}=-1$, followed by significant reductions in $\mathrm{t}=0$ and onwards. It is reasonable to expect a decrease in $B L K V$ at $\mathrm{t}=0$, the year in which the firm goes into financial distress, because the definition of financial distress is partly driven by a lackluster performance of the firm's stock price. For example, if the stock price suffers a sudden decline midway through the treatment year due to the fall into distress, then one would expect that the Black-Scholes value of stock options will decrease in the same year because the Black-Scholes value is mechanically related to the stock price. However, the observed pattern of a large increase in $t=-1$ and large decreases in years after $t=0$ is intriguing. We defer to Section 5 the detailed discussion and potential explanations for this pattern.

\subsection{Effects of Financial Distress on CEO turnover}

Another outcome variable of interest in our study is CEO turnover. One way a firm deals with its CEO who has not performed as desired by the board (and the shareholders) is to replace the CEO with a new one. Two recent studies by Jenter and Kanaan (2006) and Kaplan and Minton (2006) both show that CEO turnover rates have increased substantially in periods roughly similar to the one we analyze. Jenter and Kanaan's (2006) paper is particularly interesting for our purposes because it explicitly studies the effects of relative performance on the probability of CEO turnover. They find that, contrary to the findings of studies for earlier periods, CEOs are significantly more likely to be dismissed from their jobs after bad industry and market performance.

Our matching estimator shares the flavor of relative performance evaluation as the estimator matches and thus implicitly controls for the covariates characterizing industry and market performance. Like Jenter and Kanaan (2006) and Kaplan and Minton (2006), we find that firm 
performance has a very significant impact on CEO turnover in our sample. Table 6 reports the treatment effect of financial distress on CEO turnover using the bias-corrected matching estimator (matching on the same variables as in Table 4). In panel A, we group the years before and after the time of financial distress $(\mathrm{t}=0)$ in alternative "windows". We find that turnover rates are significantly higher for treated firms compared to control firms. For example, in the $[-1,+1]$ window, the CEO turnover rate is 20 percentage points higher for treated firms, which is a very large effect taking into account that the CEO turnover rate for the control firms is 33\%; if we extend the window by including $\mathrm{t}=+2$ or $\mathrm{t}=+3$, the CEO turnover rate further rises by 6 and 9 percentage points, respectively.

We also estimate the treatment effects on the CEO turnover rate on a year-by-year basis and report the results in Panel B. Like our results on compensation, there is no differential effect on

CEO turnover in $\mathrm{t}=-1, \mathrm{t}=-2$ or $\mathrm{t}=0$. The single most important effect on CEO turnover appears to occur in the year immediately after the treatment year (i.e., $\mathrm{t}=+1$ ), when we observe a significant treatment effect of 23 percentage points. That is, the CEO turnover rate of the distressed firms is 23 percentage points higher than the turnover rate of the non-distressed firms after the firms fall into distress. The treatment effect on CEO turnover continues into $\mathrm{t}=+2(8 \%)$ and $\mathrm{t}=+3(7 \%)$, although in a comparatively smaller magnitude than in $t=+1$.

\subsection{Effects of Financial Distress on Compensation by CEO Turnover Status}

Given the significant treatment effect on CEO turnover, a valid concern is that our documented effects of financial distress on CEO compensation are driven or confounded by the effects on CEO turnover. To separate the two treatment effects, we estimate the treatment effects of financial distress on CEO compensation for two subsamples. The first is comprised of all firms that experience CEO turnover, and the second is comprised of firms that do not experience CEO turnover. We apply the bias-corrected matching estimator to each of the two subsamples.

A caveat is in order. Given that the year $t=+1$ is the first and the single most important period with a significant difference in CEO turnover rates between the treated and control firms, we decide to consider in the turnover subsample those firms that replace their CEOs only in the period $[-1,+1]$. This restriction implies that those firms do not replace their CEOs in the periods 
$\mathrm{t}=+2$ and $\mathrm{t}=+3$, which yields a clearer comparison of the treatment effect to the subsample of no CEO turnover. For the no CEO turnover subsample we select all firms that retain the same (incumbent) CEOs over the entire $[-3,+3]$ period. $^{14}$

Table 7 presents the results for each of the two subsamples using the $D I D$ specification of the bias-corrected matching estimator. Panel A shows the treatment effects on CEO compensation for the no-turnover firms, which are very similar to the ones estimated for all the firms in Table 5. The salary, bonus, and total cash compensation of incumbent CEOs are significantly lower in and after the distress year. It is clear that the most significant and dominant effect is on stockbased compensation, particularly the Black-Scholes value of option grants. The Black-Scholes value decreases by $\$ 1.6$ million immediately in the treatment year, and continues to decline by $\$ 3$ million in the first year after the treatment, followed by reductions of $\$ 2.5$ million and $\$ 1.1$ million in the second and third year after the treatment. Like in the full sample, the treatment effect on the total flow compensation to incumbent CEOs is again overwhelmingly driven by the treatment effect on the Black-Scholes value of option grants. Notice that $B L K V$ refers to new stock options granted every year, so these decreases are pretty impressive. On the other hand, firms under financial distress tend to grant their CEOs more stock options in the post-treatment years, as evidenced by the small but statistically significant treatment effects on $O P G R N T$.

Table 7, Panel B reports the treatment effects on CEO compensation for the firms that experience CEO turnover in the period from -1 to +1 . Again, the single most important effect of financial distress on the new CEOs' compensation is on the Black-Scholes value of option grants. Relative to the control firms which also experience CEO turnover during the same window, the Black-Scholes value of the treated firms decreases by $\$ 2.6$ million in the first year after the treatment, and continues to decline by $\$ 1.7$ million in the second year after the treatment, followed by a reduction of $\$ 1.5$ million in the third year after the treatment. Same as for all the distressed firms or the distressed firms without CEO turnover, the treatment effect on the total flow compensation to new CEOs overwhelmingly reflects the effect on the Black-Scholes value of option grants. Different from the no-turnover subsample, though, financial distress appears to have a much less

\footnotetext{
${ }^{14}$ For robustness, we try different ways to form turnover versus no-turnover subsamples with different windows, like -2 to $+2,-3$ to $+3,-1$ to +2 , etc, and fit the same bias-corrected matching estimator to each subsample. The results are similar and are available upon request.
} 
and oftentimes insignificant effect on the new CEO's salary, bonus and total cash compensation, suggesting that the distressed firms award their replacement CEOs cash compensation at a level comparable to the solvent firms which also replace their CEOs.

The results for the turnover and the non-turnover subsamples suggest that CEOs of distressed firms, regardless of whether they are incumbents or successors, suffer large reductions in their compensation after the firms fall into financial distress and that this reduction derives mainly from the drop in the value of their stock option grants. This is similar to the patterns we observed in our analysis of the full sample. Consequently, we conclude that the dominant treatment effect on the stock-based compensation is not caused by the treatment effect on CEO turnover.

Also, an interesting implication arises from the results for the treated firms that do experience CEO turnover. In those firms, new CEOs are paid significantly less, in terms of stock compensation, compared both to their predecessors and to the CEOs of control firms. One might argue that paying less to CEOs of poor-performing firms is consistent with the use of benchmarking, or relative performance evaluation, by boards of directors when setting CEO compensation. However, it is hard, a priori, to argue that new CEOs should be penalized for the poor performance related to their predecessors' tenure. Moreover, when we analyze one potential "benchmark"-the performance of the firm's stock prices after a new CEO takes over-we find that the stock prices actually increase by $8 \%, 21 \%$ and $25 \%$ more in periods $\mathrm{t}=+1, \mathrm{t}=+2$ and $\mathrm{t}=+3$ respectively, compared to the stock price changes for the control firms that have also replaced their CEOs in the $[-1,+1]$ period. That is, at least in terms of stock price changes, new CEOs of the treated firms seem to be performing well relative to the benchmark, which makes it even harder to argue that financially distressed firms use benchmarking in setting CEO compensation. ${ }^{15}$

\footnotetext{
${ }^{15}$ An alternative explanation for the lower equity-based compensation for new CEOs of distressed firms, is that they are just of "worse quality" than the new CEOs of non-distressed firms. It is not easy to find good measures of "quality", and we analyze two characteristics that we believe could be good proxies. First, we look at the percentage of new CEOs that have prior experience as CEOs (i.e., having appeared as CEO of another firm in the ExecuComp dataset) or at least some prior executive experience (i.e., having appeared as one of the top five executives in another firm in the ExecuComp dataset). Second, we study internal promotions, i.e. new CEOs that have appeared as executives in the same firm before becoming CEOs. With either measure of quality, we do not observe any significant difference between the treated and the potential control firms. All the results are available upon request.
} 


\section{Explaining the Decrease in Value of Stock Option Grants}

We have documented above that the Black-Scholes value of stock option grants for the treated firms shows a spike in the year before financial distress and substantial declines in and after the year of distress. This pattern of value changes is unlikely to be driven by changes in stock prices because the market capitalization of distressed firms, which changes virtually one-to-one with stock prices, exhibits little variation from year to year after $t=0$. Nor do we observe significant reductions in the number of shares of options granted to CEOs in each post-treatment year; in fact, we find evidence that the distressed firms appear to grant more stock options to their CEOs after falling into distress. In addition, this pattern of value changes cannot be explained by changes in other parameters affecting the calculation of the Black-Scholes value: stock volatility and option maturity do not experience significant changes across the post-treatment years. Further, we follow the methodology explained at the Wharton Research Data Services (WRDS) website to calibrate the Black-Scholes value of stock option grants and find that the change in the option grant value cannot be attributed to the method used in the ExecuComp database. For brevity, the results confirming these assertions are not reported in the text and are available upon request.

Given the well-known comparative statics that the Black-Scholes value of a stock option decreases with respect to the option's exercise price, we turn to examining the dynamics of exercise prices of option grants as one likely explanation for the patten of Black-Scholes value changes. In particular, we suspect that the observed decreases in the Black-Scholes value for treated firms is related to managerial behavior of opportunistic timing of option grants. Recent studies document vast evidence of such behavior among U.S. firms. ${ }^{16}$ We conjecture that, relative to mangers of the control firms, mangers of the distressed firms engage in opportunistic timing of option grants in a greater or similar extent before the year of distress, and that managers (or the board of directors) significantly cut back or totally abandon engaging in such activity after the firm goes into distress, as the "outrage" constraint placed by the firm's various stake-holders tightens when and after a firm falls into financial distress.

\footnotetext{
${ }^{16}$ For example, Lie (2005), Heron and Lie (2006), and Narayanan and Seyhun (2008) all find that firms' abnormal stock returns are negative before executive option grants and positive afterward and attribute the stock return pattern to managerial backdating of option grants; Bebchuk, Grinstein and Peyer (2006) examine the ranking of a grant date's price in the distribution of prices during the month of the grant and show that lucky grants provide a useful tool for studying such managerial behavior.
} 


\subsection{Descriptive statistics of lucky grants}

To test our conjecture, we follow Bebchuk, Grinstein and Peyer's (2006) approach to measure opportunistic timing of CEO option grants by "lucky" grants. That is, we study how grant prices rank within the price distribution of the grant month before and after financial distress. As done in the literature, we focus on unscheduled grants of options to CEOs. ${ }^{17}$ We set the grant price, if not available, to the close price of the underlying stock on the same grant day because the common practice for option grants is to issue the options at-the-money. Moreover, Heron and Lie (2006) report that the abnormal stock return pattern consistent with the managerial option backdating behavior has been much weaker since the implementation of the regulations in the Sarbanes-Oxley Act (SOX). The SOX, which requires option grants to be reported within two business days of granting, took effect on August 29, 2002. To isolate the treatment effect of financial distress from the effect of the SOX regulation, we focus on the pre-SOX period. ${ }^{18}$

Like Bebchuk, Grinstein and Peyer (2006), we define the lucky grants as the ones whose grant prices are below or at the lowest stock price within the grant month, and we calculate the proportion of lucky grants in two ways: a raw measure, which is the number of lucky grants divided by the number of observed prices within the grant month; and a "net" measure, which is the number of lucky grants divided by the number of different trading prices within the grant month. The net measure takes into account the fact that the prices of a financially distressed stock might be "stale" in that there are few trades of such distressed stocks. For robustness, we also calculate the raw measure and the net measure weighted by the size of each option grant. The results are similar and available upon request.

Table 8 reports the descriptive statistics of the two measures of lucky grants for the treated and the potential control firms. We first analyze the statistics based on the raw measure as reported in the left panel of Table 8. Several patterns are worth mentioning. First, the proportion of lucky grants is higher for the distressed firms than for the control firms, in $t=-3$ and $t=-2$. The

\footnotetext{
${ }^{17}$ Focusing on unscheduled grants is the standard approach to studying managerial opportunistic timing behavior, but this restriction might make the evidence presented in this section not perfectly compatible with the evidence documented in Section 4. The Black-Scholes value of option grants reported in the ExecuComp database includes both scheduled and unscheduled grants. Unfortunately, the data does not contain sufficient information to calculate the Black-Scholes value for unscheduled grants only.

${ }^{18}$ We find similar pattern of lucky grants if we do not exclude the post-SOX period from our sample. The results are available upon request.
} 
proportions of lucky grants for the treated are respectively $15.1 \%$ and $19.0 \%$ in the two periods, while the corresponding proportions for the controls are respectively $13.6 \%$ and $14.3 \%$. Second, the proportions of lucky grants for the controls are quite stable during the period from $t=-1$ to $\mathrm{t}=+3$, fluctuating around the $12 \%$ level. This evidence is consistent with Bebchuk, Grinstein and Peyer's (2006) estimate of the percentage of lucky grants in their sample firms from 1996 to 2005. Third, the proportion of lucky grants for the financially distressed firms drops noticeably starting at $\mathrm{t}=-1 .{ }^{19}$ The proportions over the $[-3,+3]$ window are respectively $15.1 \%$ in $\mathrm{t}=-3,19 \%$ in $\mathrm{t}=-2$, $9.2 \%$ in $\mathrm{t}=-1,7.9 \%$ in $\mathrm{t}=0$ (i.e., the treatment year), $9.4 \%$ in $\mathrm{t}=+1,10.4 \%$ in $\mathrm{t}=+2$, and $5.2 \%$ in $\mathrm{t}=+3$. Taken together, these patterns show clearly that the proportions of lucky grants are higher for the treated than for the controls prior to financial distress and are significantly lower than for the controls from one year prior to three years after financial distress. If we take into account the effective trading of stocks and analyze the net measure of the proportion of lucky grants, the above patterns become stronger. As shown in the right half panel of Table 8, the proportions of lucky grants for the distressed firms exceed the proportions for the controls by at least 2 percentage points in either $t=-3$ or $t=-2$, but the proportions for the treated are at least 2 percentage points lower than the proportions for the controls starting from $t=-1$ and up to $t=+3$.

Table 8 also reports the descriptive statistics of the two measures for the treated and the controls in the post-SOX period. Interestingly, the proportions of lucky grants for the controls in the postSOX period drop significantly to $4.7 \%$ and $8.5 \%$ in raw measures $(0.9 \%$ and $5.1 \%$ in net measures) at $\mathrm{t}=+2$ and $\mathrm{t}=+3$, respectively. In contrast, the proportions for the controls in the pre-SOX period are $11.3 \%$ and $12.4 \%$ in raw measures $(7.1 \%$ and $8.2 \%$ in net measures $)$ at $t=+2$ and $\mathrm{t}=+3$, respectively. This result suggests that the SOX regulations help curtail opportunistic managerial behavior in timing option grants, consistent with the finding documented by Heron and Lie (2006). Furthermore, the proportions of lucky grants for the financially distressed firms are still smaller than the proportions for the controls after the distress episode in the pre-SOX period, but the gap narrows in the post-SOX period.

\footnotetext{
${ }^{19}$ Note that, as explained in Footnote 17, the calculation of the Black-Scholes value of option grants includes both scheduled and unscheduled grants, while the analysis of lucky grants is based only on unscheduled grants. This may explain why the proportion of lucky grants starts decreasing in $t=-1$ and the Black-Scholes value of option grants starts decreasing in $\mathrm{t}=0$.
} 


\subsection{Treatment Effects of Distress on the Proportion of Lucky Grants}

In this subsection we consider the proportion of lucky grants as another outcome variable of interest. Thus, we estimate the treatment effect of financial distress on the proportion of lucky grants, using the same set of matching covariates as we use above for the analysis of CEO compensation. Table 9 reports the results based on the matching estimators both in levels (Panel A) and in differences (Panel B).

We first look at the results for the in-level estimates (Panel A). Although many of the estimates are not statistically different from zero, the in-level results exhibit a pattern of changes in lucky option grants similar to the one obtained from the descriptive statistics. Using either the raw measure or the net measure, the estimated treatment effect on the proportion of lucky grants is positive in $\mathrm{t}=-2$, suggesting that before distress, treated firms tend to award their CEOs more lucky grants than the control firms. However, the treatment effects become negative starting at $\mathrm{t}=-1$ and remain negative through $\mathrm{t}=+3$, indicating that the treated firms significantly cut back the lucky grants to their CEOs. In particular, the in-level treatment effects are significantly different from zero for $t=0$ and $t=+1$ : based on the raw measure, the estimate is $-6.5 \%$ and significant at the $10 \%$ level in $\mathrm{t}=0$, and it is $-8.7 \%$ and significant at the $5 \%$ level in $\mathrm{t}=+1$; based on the net measure, the estimates are $-7.2 \%$ and $-8.9 \%$ in $t=0$ and $t=+1$, respectively, and both are significant at the $5 \%$ level. Although the level estimates of the treatment effect for $\mathrm{t}=+2$ or $\mathrm{t}=+3$ are not statistically significant, the magnitudes of the level estimates are by no means small: the estimates are about $-4.5 \%$ using the raw measure and about $-5.0 \%$ using the net measure.

In Table 9, panel $\mathrm{B}$ we present the results for the $D I D$ estimates, with the difference taken relative to the proportion of lucky grants in $\mathrm{t}=-3$. Unfortunately, the $D I D$ effects are much more imprecisely estimated, making them not statistically significant. However, the $D I D$ point estimates of the treatment effect on the proportion of lucky grants display a similar pattern to the level estimates obtained above.

In summary, both the summary statistics and the matching estimators show evidence that there is a change in the behavior of awarding lucky grants to CEOs of firms under financial distress before and after falling into distress. The soon-to-be insolvent firms tend to award their CEOs more lucky grants than comparable solvent firms two years prior to insolvency, but those firms significantly 
scale down the lucky grants to their CEOs upon or after they become financially distressed while the comparable solvent firms maintain about the same level of lucky option grants.

The pattern of decreases in lucky option grants for the treated firms after financial distress is consistent with the pattern of declines in the Black-Scholes value of stock option grants as documented in Section 4 for those firms. In view of the Bebchuk, Grinstein and Peyer's (2006) finding that the likelihood of lucky grants is positively associated with the CEO power to set their own pay, we interpret our evidence as indicative of a decrease in managerial power caused by the tightening of the "outrage" constraint as a result of falling into financial distress. Moreover, this change in the behavior of awarding lucky grants to CEOs by firms under financial distress can also explain why even new CEOs of the distressed firms see their stock-based compensation decrease significantly relative to either their ousted predecessors or CEOs of comparable but solvent firms.

\section{Conclusion}

We study the effects of financial distress on the CEO compensation practices of U.S. public companies between 1992 and 2005. We match financially distressed firms with control firms using Abadie and Imbens' (2006, 2007) non-parametric bias-corrected matching estimators. We find that the CEOs of distressed firms experience significant reductions in both their cash compensation and total flow compensation relative to CEOs of control firms. Also, CEO turnover rates increase markedly following financial distress. Moreover, the significant reductions in compensation among the set of financially distressed firms occurs for both new CEOs and incumbent CEOs. The bulk of the reduction in total compensation comes from the decline in the Black-Scholes value of stock option grants. The large drop in option grant values for CEOs of the distressed firms is not explained by stock volatility, stock price, option maturity, or the method used to calculate the Black-Scholes value.

We proceed to examine the dynamics of managerial opportunistic timing of option grants before and after financial distress. We follow Bebchuk, Grinstein and Peyer's (2006) approach to focus on how grant prices rank within the price distribution of the grant month, and we define lucky grants

as the ones with grant prices below or at the lowest stock price of the grant month. We find that the proportions of lucky grants for the treated firms are higher before falling into financial distress and 
lower upon and after becoming distressed, compared to similar but non-distressed firms. That is, the treated firms tend to award their CEOs more lucky grants prior to insolvency but significantly reduce the lucky grants to their CEOs upon or after insolvency, while the solvent firms maintain about the same level of lucky option grants.

We argue that the pattern of decreases in lucky option grants for treated firms after financial distress is consistent with the pattern of declines in the Black-Scholes value of stock option grants for those firms. We interpret our evidence as indicative of a decrease in managerial power caused by the tightening of the "outrage" constraint due to the episode of financial distress. 


\section{References}

[1] Abadie, Alberto, David Drukker, Jane Leber Herr, and Guido W. Imbens, 2004. Implementing matching estimators for average treatment effects in Stata. Stata Journal 4(3): 290-311.

[2] Abadie, Alberto, and Guido W. Imbens, 2006. Large Sample Properties of Matching Estimators for Average Treatment Effects. Econometrica 74, No. 1: 235-267.

[3] Abadie, Alberto, and Guido W. Imbens, 2007. Bias Corrected Matching Estimators for AverageTreatment Effects. Harvard University Working Paper, August.

[4] Abadie, Alberto, and Guido W. Imbens, forthcoming. On the Failure of the Bootstrap for Matching Estimators. Econometrica.

[5] Aggarwal, R., Samwick, A., 1999. The other side of the trade-off: The impact of risk on executive compensation. Journal of Political Economy 107, 65-105.

[6] Aseff, Jorge G., and Manuel S. Santos, 2005. Stock options and managerial optimal contracts. Economic Theory 26, 813837.

[7] Bebchuk, Lucian, and Jesse Fried, 2003. Executive compensation as an agency problem. Journal of Economic Perspectives 17, 71-92.

[8] Bebchuk, Lucian, and Jesse Fried, 2004. Pay without performance: The unfulfilled promise of executive compensation. Harvard University Press. Cambridge, MA.

[9] Bebchuk, Lucian, and Yaniv Grinstein, 2005. The growth of executive pay. Oxford Review of Economic Policy, 21, 283-303.

[10] Bebchuk, Lucian, Yaniv Grinstein, and Urs Peyer, 2006, Lucky CEOs, NBER Working Paper 12771.

[11] Bertrand, Marian, and Sendhil Mullainathan, 2001. Are CEOs rewarded for luck? The ones without principals do. Quarterly Journal of Economics, 116, 901-932.

[12] Core, J., W. Guay, and D. Larcker, 2003. Executive equity compensation and incentives: A survey. Federal Reserve Bank of New York Economic Policy Review 9, 27-50.

[13] Garvey, Gerald T., and Todd Milbourn, 2006, Asymmetric benchmarking in compensation: Executives are rewarded for good luck but not penalized for bad, Journal of Financial Economics, 82, 197225.

[14] Gibbons, Robert, and Kevin J. Murphy, 1990. Relative performance evaluation for chief executive officiers. Industry and Labor Reations Review 43, 30-51.

[15] Gilson, Stuart C., 1989. Management turnover and financial distress. Journal of Financial Economics, 25, 241-262.

[16] Gilson, Stuart C., and Michael R. Vetsuypens, 1993. CEO compensation in financially distressed firms: An empirical analysis. Journal of Finance, 48, 425-458.

[17] Government Printing Office (GPO), 2008. Emergency Economic Stabilization Act of 2008. Accesed on October 27, 2008 at http://frwebgate.access.gpo.gov/cgibin/getdoc.cgi?dbname=110_cong_bills\&docid=f:h1424enr.txt.pdf. 
[18] Hall, Brian, and Joseph Liebman, 1998. Are CEOs really paid like bureaucrats?. Quarterly Journal of Economics 113, 653-691.

[19] Haubrich, Joseph, 1994. Risk aversion, performance pay, and the principal-agent problem. Journal of Political Economy 102, 258276.

[20] Heckman, James J, and V. Joseph Hotz, 1989. Choosing among alternative nonexperimental methods for estimating the impact of social programs: The case of manpower training. Journal of the American Statistical Association 84, no. 408, 862-874.

[21] Heron, Randall A., and Erik Lie, 2006. Does backdaing explain the stock price pattern around executive stock option grants?, Journal of Financial Economics 83, 271-295.

[22] Huson, M. R., R. Parrino, and L.T. Starks, 2001. Internal monitoring mechanisms and CEO turnover: A long term perspective. Journal of Finance 56, 2265-2297.

[23] Jensen, Michael, and Kevin J. Murphy, 1990. Performance pay and top-management incentives. Journal of Political Economy, 98, 225-262.

[24] Jenter, Dirk, and Fadi Kanaan, 2006. CEO turnover and relative performance evaluation. National Bureau of Economic Research Working Paper Series No. 12068.

[25] Kaplan, Steven N., and Bernadette Minton, 2006. How has CEO turnover changed? Increasingly performance sensitive boards and increasingly uneasy CEOs. National Bureau of Economic Research Working Paper Series No. 12465.

[26] Lie, E., 2005. On the timing of CEO Stock Option Awards, Management Science 51, 802-812.

[27] LoPucki, Lynn, 2005. Courting failure: How competition for big cases is corrupting the bankruptcy courts. University of Michigan Press. Ann Arbor, MI.

[28] Murphy, Kevin J., 1999. Executive compensation, in: Orley Ashenfelter and David Card, (eds), Handbook of Labor Economics, Vol. 3, North Holland.

[29] Narayanan, M. P. and H. Nejat Seyhun, 2008. The dating game: Do managers designate grant dates to increase their compensation? Review of Financial Studies 21(5), 1907-1945.

[30] Ohlson, James A., 1980. Financial ratios and the probabilistic prediction of bankruptcy. Journal of Accounting Research, 18, 109-131.

[31] Warner, J.B., R.L. Watts, and K. Wruck, 1988. Stock prices and top management changes. Journal of Financial Economics 20, 461-492.

[32] The Wall Street Journal, October 31, 2008, Banks Owe Billions to Executives (by Ellen E. Schultz).

[33] Weisbach, M., 1988. Outside Directors and CEO Turnover. Journal of Financial Economics, 20, 431-460. 
Table 1. Number of treated and potential control observations per fiscal year

\begin{tabular}{|c|c|c|}
\hline \multirow{2}{*}{$\begin{array}{c}\text { Fiscal } \\
\text { Year }\end{array}$} & \multicolumn{2}{|c|}{ Analysis sample } \\
\hline & Treated & Pot. Controls \\
\hline 1995 & 11 & 173 \\
\hline 1996 & 7 & 92 \\
\hline 1997 & 8 & 71 \\
\hline 1998 & 15 & 84 \\
\hline 1999 & 15 & 200 \\
\hline 2000 & 11 & 72 \\
\hline 2001 & 15 & 371 \\
\hline 2002 & 17 & 142 \\
\hline Total & 99 & 1,205 \\
\hline
\end{tabular}

Note:

The analysis sample is formed by all the firms with no missing information in the matching or compensation variables in period -3 , and at most one missing variable among all compensation variables in periods -2 to 0 and at most one missing variable in all compensation variables in periods 1 to 3 .

Table 2. CEO Turnover rates

\begin{tabular}{c|cc|cc|cc}
$\begin{array}{c}\text { Turnover } \\
\text { in Period }\end{array}$ & \multicolumn{2}{|c|}{ Turnover Rate } & \multicolumn{2}{c|}{ Treated (\# Obs.) } & \multicolumn{2}{c}{ Pot. Controls (\# Obs.) } \\
\hline$[-1,+1]$ & Treated & Pot. Controls & No Turnover & Turnover & No Turnover & Turnover \\
\hline$[-1,+2]$ & $52 \%$ & $33 \%$ & 47 & 51 & 812 & 391 \\
{$[-1,+3]$} & $63 \%$ & $41 \%$ & 36 & 61 & 711 & 490 \\
{$[-2,+2]$} & $69 \%$ & $48 \%$ & 29 & 65 & 559 & 514 \\
{$[-2,+3]$} & $69 \%$ & $47 \%$ & 33 & 64 & 636 & 557 \\
{$[-3,+3]$} & $69 \%$ & $53 \%$ & 29 & 65 & 496 & 570 \\
\end{tabular}

Note: The sum of the number of observations in the no turnover and turnover groups does not add-up to the total number of observations because for some firms turnover information is missing in some years. 
Table 3. Descriptive statistics for outcome variables

\begin{tabular}{|c|c|c|c|c|c|c|c|}
\hline \multirow[t]{2}{*}{ Variable } & \multirow[t]{2}{*}{ Period } & \multicolumn{3}{|c|}{ Treated } & \multicolumn{3}{|c|}{ Potential Controls } \\
\hline & & Mean & S.D. & $\mathbf{N}$ & Mean & S.D. & $\mathbf{N}$ \\
\hline \multirow{7}{*}{$\begin{array}{l}\text { Salary } \\
\text { (\$ millions) }\end{array}$} & -3 & 0.5 & 0.3 & 97 & 0.6 & 0.3 & 1,203 \\
\hline & -2 & 0.6 & 0.3 & 97 & 0.7 & 0.3 & 1,195 \\
\hline & -1 & 0.6 & 0.3 & 97 & 0.7 & 0.3 & 1,203 \\
\hline & 0 & 0.6 & 0.4 & 97 & 0.7 & 0.4 & 1,201 \\
\hline & +1 & 0.5 & 0.3 & 96 & 0.7 & 0.4 & 1,202 \\
\hline & +2 & 0.6 & 0.3 & 96 & 0.7 & 0.4 & 1,201 \\
\hline & +3 & 0.6 & 0.3 & 94 & 0.8 & 0.4 & 1,075 \\
\hline \multirow{7}{*}{$\begin{array}{l}\text { Bonus } \\
\text { ( } \$ \text { millions) }\end{array}$} & -3 & 0.4 & 0.5 & 97 & 0.5 & 0.5 & 1,203 \\
\hline & -2 & 0.4 & 0.6 & 97 & 0.6 & 0.9 & 1,195 \\
\hline & -1 & 0.2 & 0.6 & 97 & 0.6 & 0.8 & 1,203 \\
\hline & 0 & 0.1 & 0.3 & 97 & 0.6 & 0.9 & 1,201 \\
\hline & +1 & 0.3 & 0.5 & 96 & 0.7 & 1.0 & 1,202 \\
\hline & +2 & 0.4 & 0.5 & 96 & 0.8 & 1.1 & 1,201 \\
\hline & +3 & 0.5 & 0.6 & 94 & 0.9 & 1.1 & 1,075 \\
\hline \multirow{7}{*}{$\begin{array}{l}\text { TCC = Total Current } \\
\text { Compensation } \\
\text { (Salary + Bonus) } \\
\text { (\$ millions) }\end{array}$} & -3 & 0.9 & 0.7 & 97 & 1.1 & 0.8 & 1,203 \\
\hline & -2 & 1.0 & 0.8 & 97 & 1.2 & 1.1 & 1,195 \\
\hline & -1 & 0.9 & 0.8 & 97 & 1.3 & 1.0 & 1,203 \\
\hline & 0 & 0.7 & 0.6 & 97 & 1.3 & 1.2 & 1,201 \\
\hline & +1 & 0.9 & 0.7 & 96 & 1.4 & 1.2 & 1,202 \\
\hline & +2 & 1.0 & 0.7 & 96 & 1.5 & 1.3 & 1,201 \\
\hline & +3 & 1.1 & 0.8 & 94 & 1.6 & 1.4 & 1,075 \\
\hline \multirow{7}{*}{$\begin{array}{l}\text { BLKV = Black- } \\
\text { Scholes Value of } \\
\text { Option Grants } \\
\text { (\$ millions) }\end{array}$} & -3 & 1.9 & 3.6 & 97 & 1.2 & 2.4 & 1,203 \\
\hline & -2 & 3.0 & 9.0 & 97 & 2.5 & 8.1 & 1,191 \\
\hline & -1 & 4.8 & 15.4 & 97 & 2.3 & 5.7 & 1,195 \\
\hline & 0 & 1.1 & 2.5 & 97 & 2.6 & 5.5 & 1,192 \\
\hline & +1 & 0.9 & 1.1 & 95 & 2.8 & 10.0 & 1,193 \\
\hline & +2 & 1.1 & 1.8 & 95 & 2.8 & 6.6 & 1,193 \\
\hline & +3 & 1.9 & 5.0 & 91 & 2.6 & 6.8 & 1,068 \\
\hline \multirow{8}{*}{$\begin{array}{l}\text { RSTGRNT = } \\
\text { Restricted Stock } \\
\text { Grants Value } \\
\text { (\$ millions) }\end{array}$} & -3 & 0.2 & 0.8 & 97 & 0.1 & 0.5 & 1,203 \\
\hline & -2 & 0.1 & 0.8 & 97 & 0.2 & 1.0 & 1,195 \\
\hline & -1 & 0.1 & 0.7 & 97 & 0.3 & 1.0 & 1,203 \\
\hline & 0 & 0.1 & 0.4 & 97 & 0.4 & 1.5 & 1,201 \\
\hline & +1 & 0.2 & 0.6 & 96 & 0.4 & 1.6 & 1,202 \\
\hline & +2 & 0.2 & 0.6 & 96 & 0.4 & 1.5 & 1,201 \\
\hline & +3 & 0.3 & 1.0 & 94 & 0.7 & 2.3 & 1,075 \\
\hline & -3 & 3.2 & 4.9 & 97 & 2.7 & 3.1 & 1,203 \\
\hline \multirow{6}{*}{$\begin{array}{l}\text { TDC1 = Total Direct } \\
\text { Compensation } 1 \\
\text { (TCC + BLKV + } \\
\text { RSTGRNT + Others) } \\
\text { (\$ millions) }\end{array}$} & -2 & 4.4 & 9.8 & 97 & 4.3 & 8.9 & 1,191 \\
\hline & -1 & 6.3 & 17.2 & 97 & 4.3 & 6.7 & 1,195 \\
\hline & 0 & 2.4 & 3.5 & 97 & 4.7 & 7.0 & 1,192 \\
\hline & +1 & 2.3 & 2.5 & 95 & 5.1 & 11.0 & 1,193 \\
\hline & +2 & 2.6 & 3.1 & 95 & 5.2 & 8.2 & 1,193 \\
\hline & +3 & 3.9 & 6.4 & 91 & 5.6 & 9.6 & 1,068 \\
\hline \multirow{8}{*}{$\begin{array}{l}\text { EXER = Value } \\
\text { Realized from } \\
\text { Options Exercises } \\
(\$ \text { millions })\end{array}$} & -3 & 1.1 & 4.2 & 96 & 1.4 & 5.9 & 1,190 \\
\hline & -2 & 5.5 & 18.5 & 97 & 1.8 & 6.6 & 1,194 \\
\hline & -1 & 2.7 & 14.7 & 97 & 1.8 & 6.6 & 1,202 \\
\hline & 0 & 0.1 & 0.3 & 97 & 1.6 & 5.8 & 1,197 \\
\hline & +1 & 0.1 & 0.3 & 96 & 1.9 & 8.4 & 1,201 \\
\hline & +2 & 0.4 & 1.5 & 95 & 1.8 & 6.6 & 1,199 \\
\hline & +3 & 0.3 & 1.3 & 93 & 2.7 & 10.7 & 1,072 \\
\hline & -3 & 2.6 & 4.8 & 97 & 2.8 & 6.4 & 1,203 \\
\hline \multirow{6}{*}{$\begin{array}{l}\text { TDC2 = Total Direct } \\
\text { Compensation } 2 \\
(\text { TCC + EXER + } \\
\text { RSTGRNT + Others }) \\
\text { (\$ millions) }\end{array}$} & -2 & 7.2 & 19.8 & 97 & 3.6 & 7.8 & 1,195 \\
\hline & -1 & 4.3 & 16.7 & 97 & 3.8 & 7.4 & 1,203 \\
\hline & 0 & 1.2 & 1.6 & 97 & 3.7 & 6.8 & 1,201 \\
\hline & +1 & 1.6 & 1.9 & 96 & 4.2 & 9.4 & 1,202 \\
\hline & +2 & 2.0 & 2.7 & 96 & 4.3 & 8.0 & 1,201 \\
\hline & +3 & 2.2 & 3.1 & 94 & 5.7 & 13.5 & 1,075 \\
\hline
\end{tabular}


Table 4. Balancing of covariates used in matching

\begin{tabular}{|c|c|c|c|c|c|c|c|c|}
\hline \multirow[t]{2}{*}{ Variable } & \multicolumn{2}{|c|}{ Treated } & \multicolumn{2}{|c|}{ Pot. Controls } & \multicolumn{2}{|c|}{ Raw Difference } & \multicolumn{2}{|c|}{ |Within Matches Diff } \\
\hline & Mean & S.D. & Mean & S.D. & Mean & S.E. & Mean & S.E. \\
\hline Fiscal Year 1995 & 0.11 & 0.32 & 0.14 & 0.35 & -0.03 & 0.03 & 0.01 & 0.01 \\
\hline Fiscal Year 1996 & 0.07 & 0.26 & 0.08 & 0.27 & -0.01 & 0.03 & 0.00 & 0.00 \\
\hline Fiscal Year 1997 & 0.08 & 0.27 & 0.06 & 0.24 & 0.02 & 0.03 & 0.00 & 0.00 \\
\hline Fiscal Year 1998 & 0.15 & 0.36 & 0.07 & 0.25 & $0.08^{*}$ & 0.04 & 0.00 & 0.00 \\
\hline Fiscal Year 1999 & 0.15 & 0.36 & 0.17 & 0.37 & -0.01 & 0.04 & 0.01 & 0.01 \\
\hline Fiscal Year 2000 & 0.11 & 0.32 & 0.06 & 0.24 & 0.05 & 0.03 & 0.00 & 0.00 \\
\hline Fiscal Year 2001 & 0.15 & 0.36 & 0.31 & 0.46 & $-0.16^{\star *}$ & 0.04 & 0.00 & 0.01 \\
\hline Fiscal Year 2002 & 0.17 & 0.38 & 0.12 & 0.32 & 0.05 & 0.04 & -0.02 & 0.02 \\
\hline Dummy SIC = 1 - Consumer Industries/Services & 0.19 & 0.40 & 0.26 & 0.44 & -0.06 & 0.04 & 0.01 & 0.01 \\
\hline Dummy SIC = 2 - Manufacturing, Energy \& Utilities & 0.23 & 0.42 & 0.34 & 0.47 & $-0.11^{*}$ & 0.04 & 0.00 & 0.01 \\
\hline Dummy SIC = 3 - Business Equipment, Telecomm, TV & 0.34 & 0.48 & 0.22 & 0.41 & $0.12^{*}$ & 0.05 & 0.02 & 0.02 \\
\hline Dummy SIC = 4 - Healthcare, Medical Equp \& Drugs & 0.07 & 0.26 & 0.07 & 0.25 & 0.00 & 0.03 & 0.00 & 0.01 \\
\hline Dummy SIC = 5 - Other Industries & 0.16 & 0.37 & 0.11 & 0.32 & 0.05 & 0.04 & 0.03 & 0.03 \\
\hline Log of Market Capitalization in $t=-3$ & 6.99 & 1.39 & 7.24 & 1.44 & -0.25 & 0.15 & $-0.22^{* *}$ & 0.08 \\
\hline Dummy Large Market Cap (70th percentile) in $\mathrm{t}=-3$ & 0.56 & 0.50 & 0.63 & 0.48 & -0.08 & 0.05 & -0.05 & 0.03 \\
\hline Total Liabilities/Total Assets in $t=-3$ & 0.48 & 0.24 & 0.49 & 0.19 & 0.00 & 0.02 & 0.00 & 0.01 \\
\hline O-Score in $\mathrm{t}=-3$ & 0.20 & 0.21 & 0.15 & 0.16 & $0.06^{\star *}$ & 0.02 & $0.03^{\star *}$ & 0.01 \\
\hline Cumulutive Stock Return in $t=[-3,-5]$ & 0.48 & 1.07 & 0.24 & 0.51 & $0.24^{*}$ & 0.11 & 0.04 & 0.02 \\
\hline Dummy Top Quantile O-Score Distribution in $t=-3$ & 0.09 & 0.29 & 0.02 & 0.15 & $0.07^{\star}$ & 0.03 & 0.00 & 0.00 \\
\hline Dummy Bottom Quantile Cum Stock Return Dist in $\mathrm{t}=-3$ & 0.06 & 0.24 & 0.04 & 0.20 & 0.02 & 0.02 & 0.01 & 0.01 \\
\hline Total Current Compensation $(\mathrm{TCC})(\$ \mathrm{~m})$ in $\mathrm{t}=-3$ & 1.01 & 1.07 & 1.09 & 0.76 & -0.08 & 0.11 & -0.06 & 0.05 \\
\hline Total Direct Compensation $1(\mathrm{TDC} 1)(\$ \mathrm{~m})$ in $\mathrm{t}=-3$ & 3.56 & 6.47 & 2.75 & 3.28 & 0.81 & 0.66 & 0.41 & 0.33 \\
\hline Number of Observations & & & & & & & & \\
\hline
\end{tabular}

Note: The number of observations of the within matches difference, reflects that 4 matches where selected for each treated firm.

* significant at $5 \%$; * significant at $1 \%$ 
Table 5. Average Treatment Effect for the Treated (ATT) of financial distress Outcome variables in differences with respect to their values in period -3

A. Simple Matching Estimator

\begin{tabular}{|c|c|c|c|c|c|c|c|c|c|}
\hline Period & Salary & Bonus & TCC & BLKV & RSTGRNT & TDC1 & EXER & TDC2 & OPGRNT \\
\hline \multirow[t]{2}{*}{-2} & 0.0 & -0.1 & -0.1 & 0.3 & $-0.3^{*}$ & 0.2 & $2.9^{\star}$ & $3.4^{\star \star}$ & 0.0 \\
\hline & $(0.0)$ & $(0.1)$ & $(0.1)$ & $(0.8)$ & $(0.2)$ & (1.0) & (1.6) & (1.6) & $(0.0)$ \\
\hline \multirow[t]{2}{*}{-1} & 0.0 & $-0.3^{\star \star \star}$ & $-0.3^{\star * \star}$ & 1.1 & $-0.2^{\star *}$ & 0.6 & 2.2 & 1.6 & 0.0 \\
\hline & $(0.0)$ & $(0.1)$ & $(0.1)$ & (1.7) & $(0.1)$ & (1.8) & (1.9) & (1.6) & $(0.0)$ \\
\hline \multirow[t]{2}{*}{0} & $-0.1^{\star \star \star}$ & $-0.5^{\star \star \star}$ & $-0.5^{\star \star \star}$ & $-2.3^{\star \star \star}$ & $-0.3^{\star \star \star}$ & $-3.3^{\star \star \star}$ & -0.4 & $-1.7^{*}$ & 0.0 \\
\hline & $(0.0)$ & $(0.1)$ & $(0.1)$ & $(0.4)$ & $(0.1)$ & $(0.6)$ & (1.2) & (1.0) & $(0.0)$ \\
\hline \multirow[t]{2}{*}{+1} & $-0.1^{\star \star \star}$ & $-0.4^{\star \star \star}$ & $-0.4^{\star \star \star}$ & $-4.2^{\star \star \star}$ & -0.1 & $-5.3^{\star \star \star}$ & -0.7 & $-2.0^{\star \star}$ & $0.1^{*}$ \\
\hline & $(0.0)$ & $(0.1)$ & $(0.1)$ & (0.8) & (0.1) & $(1.0)$ & (1.2) & (0.9) & (0.0) \\
\hline \multirow[t]{2}{*}{+2} & $-0.1^{\star \star *}$ & $-0.3^{\star \star \star}$ & $-0.4^{\star \star *}$ & $-3.3^{\star \star *}$ & $-0.2^{*}$ & $-4.0^{\star \star \star *}$ & -0.1 & -1.1 & 0.0 \\
\hline & $(0.0)$ & $(0.1)$ & $(0.1)$ & $(0.6)$ & $(0.1)$ & $(0.7)$ & (1.2) & (1.3) & $(0.0)$ \\
\hline \multirow[t]{2}{*}{+3} & $-0.1^{\star \star \star}$ & $-0.2^{\star \star \star}$ & $-0.3^{\star \star \star}$ & $-1.3^{*}$ & $-0.5^{\star \star}$ & $-2.1^{\star \star}$ & -1.3 & $-2.8^{*}$ & $0.1^{\star \star}$ \\
\hline & $(0.0)$ & $(0.1)$ & $(0.1)$ & $(0.7)$ & $(0.2)$ & $(0.9)$ & (1.3) & (1.4) & $(0.0)$ \\
\hline
\end{tabular}

B. Bias-Corrected Matching Estimator

\begin{tabular}{|c|c|c|c|c|c|c|c|c|c|}
\hline Period & Salary & Bonus & TCC & BLKV & RSTGRNT & TDC1 & EXER & TDC2 & OPGRNT \\
\hline \multirow[t]{2}{*}{-2} & 0.0 & -0.1 & -0.1 & 0.5 & -0.2 & 0.4 & $2.9^{*}$ & $3.1^{*}$ & 0.0 \\
\hline & $(0.0)$ & $(0.1)$ & (0.1) & (0.8) & $(0.2)$ & (1.0) & (1.6) & (1.6) & $(0.0)$ \\
\hline \multirow[t]{2}{*}{-1} & 0.0 & $-0.3^{\star \star \star}$ & $-0.3^{\star \star \star}$ & 1.0 & $-0.2^{\star \star}$ & 0.6 & 1.2 & 0.6 & 0.0 \\
\hline & $(0.0)$ & $(0.1)$ & $(0.1)$ & $(1.7)$ & $(0.1)$ & $(1.8)$ & (1.9) & (1.6) & $(0.0)$ \\
\hline \multirow[t]{2}{*}{0} & $-0.1^{\star \star \star}$ & $-0.5^{\star \star \star}$ & $-0.5^{\star \star \star}$ & $-2.3^{\star \star \star}$ & $-0.2^{\star \star}$ & $-3.2^{\star \star \star}$ & -1.6 & $-2.6^{\star \star}$ & 0.0 \\
\hline & $(0.0)$ & $(0.1)$ & $(0.1)$ & $(0.4)$ & $(0.1)$ & $(0.6)$ & (1.2) & $(1.0)$ & $(0.0)$ \\
\hline \multirow[t]{2}{*}{+1} & $-0.1^{\star \star \star}$ & $-0.4^{\star \star \star}$ & $-0.4^{\star \star \star}$ & 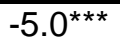 & -0.1 & $-5.8^{\star \star \star}$ & $-2.0^{\star}$ & $-3.1^{\star \star \star}$ & $0.1^{\star \star}$ \\
\hline & $(0.0)$ & $(0.1)$ & $(0.1)$ & $(0.8)$ & $(0.1)$ & $(1.0)$ & $(1.2)$ & $(0.9)$ & $(0.0)$ \\
\hline \multirow[t]{2}{*}{+2} & $-0.1^{\star \star \star}$ & $-0.3^{\star \star \star}$ & $-0.4^{\star \star \star}$ & $-2.7^{\star \star \star}$ & $-0.2^{\star}$ & $-3.5^{\star \star \star}$ & -0.5 & -1.8 & 0.0 \\
\hline & $(0.0)$ & $(0.1)$ & $(0.1)$ & $(0.6)$ & (0.1) & $(0.7)$ & (1.2) & (1.3) & $(0.0)$ \\
\hline \multirow[t]{2}{*}{+3} & $-0.1^{\star \star \star}$ & $-0.2^{\star \star \star}$ & $-0.3^{\star \star \star}$ & -0.7 & $-0.5^{\star \star}$ & -1.3 & $-2.4^{\star}$ & $-3.6^{\star \star}$ & $0.1^{\star \star}$ \\
\hline & $(0.0)$ & $(0.1)$ & $(0.1)$ & $(0.7)$ & $(0.2)$ & $(0.9)$ & (1.3) & $(1.4)$ & $(0.0)$ \\
\hline
\end{tabular}

Notes:

Robust standard errors in parentheses

* significant at 10\%; ** significant at 5\%*; *** significant at $1 \%$

All variables are expressed in \$ millions, except for OPGRNT

TCC = Total Current Compensation (Salary + Bonus)

BLKV = Black-Scholes Value of Option Grants

RSTGRNT = Restricted Stock Grants Value

TDC1 = Total Direct Compensation 1 (TCC + BLKV + RSTGRNT + Others)

EXER = Value Realized from Option Exercises

TDC2 = Total Direct Compensation 2 (TCC + EXER + RSTGRNT + Others)

OPGRNT = Log(Option Shares Granted / Total Shares Outstanding) 
Table 6. ATT of financial distress on turnover rates Bias-Corrected Matching Estimator

A. Turnover rates by several years periods

\begin{tabular}{c|llllll} 
Period & {$[-1,+1]$} & {$[-1,+2]$} & {$[-1,+3]$} & {$[-2,+2]$} & {$[-2,+3]$} & {$[-3,+3]$} \\
\hline ATT & $0.20^{\star \star \star}$ & $0.26^{\star \star \star}$ & $0.29^{\star \star \star}$ & $0.23^{\star \star \star}$ & $0.22^{\star \star \star}$ & $0.22^{\star \star \star}$ \\
S.E. & $(0.06)$ & $(0.06)$ & $(0.06)$ & $(0.06)$ & $(0.06)$ & $(0.06)$
\end{tabular}

B. Turnover rates period-by-period

\begin{tabular}{c|cccccc} 
Period & $\mathbf{- 2}$ & $\mathbf{- 1}$ & $\mathbf{0}$ & $\mathbf{+ 1}$ & $\mathbf{+ 2}$ & $\mathbf{+ 3}$ \\
\hline ATT & -0.01 & 0.06 & -0.02 & $0.23^{\star \star \star}$ & $0.08^{\star \star}$ & $0.07^{\star}$ \\
S.E. & $(0.03)$ & $(0.04)$ & $(0.04)$ & $(0.05)$ & $(0.04)$ & $(0.04)$
\end{tabular}

Notes:

Robust standard errors in parentheses

* significant at $10 \%$; ** significant at $5 \% *$; *** significant at $1 \%$ 
Table 7. Average Treatment Effect for the Treated (ATT) of financial distress - By CEO Turnover Outcome variables in differences with respect to their values in period -3 Bias-Corrected Matching Estimator

\section{A. Firms w/No CEO Turnover in $[-3,+3]$}

\begin{tabular}{|c|c|c|c|c|c|c|c|c|c|}
\hline Period & Salary & Bonus & TCC & BLKV & RSTGRNT & TDC1 & EXER & TDC2 & OPGRNT \\
\hline \multirow[t]{2}{*}{-2} & 0.0 & $-0.2^{\star \star}$ & -0.1 & 0.1 & 0.0 & 0.0 & 0.5 & 1.1 & $0.2^{\star \star \star}$ \\
\hline & $(0.0)$ & $(0.1)$ & $(0.1)$ & $(0.8)$ & $(0.0)$ & $(1.1)$ & $(0.6)$ & $(0.8)$ & (0.1) \\
\hline \multirow[t]{2}{*}{-1} & 0.0 & $-0.4^{\star * *}$ & $-0.3^{\star \star \star}$ & $-1.8^{\star \star \star}$ & 0.0 & $-2.0^{\star \star \star}$ & -0.3 & -0.7 & $0.3^{\star \star \star}$ \\
\hline & $(0.0)$ & $(0.1)$ & $(0.1)$ & $(0.5)$ & $(0.0)$ & $(0.7)$ & $(0.3)$ & $(0.4)$ & $(0.1)$ \\
\hline \multirow[t]{2}{*}{0} & $-0.1^{* \star}$ & $-0.4^{\star \star \star}$ & $-0.4^{\star \star \star}$ & $-1.6^{\star \star \star}$ & $-0.2^{\star \star}$ & $-1.9^{\star \star \star}$ & -1.0 & -2.9 & $0.5^{\star \star \star}$ \\
\hline & $(0.0)$ & $(0.1)$ & $(0.1)$ & $(0.6)$ & $(0.1)$ & $(0.7)$ & $(1.9)$ & (1.9) & (0.1) \\
\hline \multirow[t]{2}{*}{+1} & $-0.1^{\star \star \star}$ & $-0.4^{\star \star \star}$ & $-0.5^{\star \star \star}$ & $-3.0^{\star \star \star}$ & -0.1 & $-3.2^{\star \star \star}$ & $-3.4^{\star \star \star}$ & $-3.8^{\star \star \star}$ & $0.1^{*}$ \\
\hline & $(0.0)$ & $(0.1)$ & $(0.1)$ & $(0.5)$ & (0.1) & $(0.7)$ & $(0.9)$ & $(1.0)$ & (0.1) \\
\hline \multirow{2}{*}{+2} & $-0.1^{\star \star \star}$ & $-0.3^{\star \star}$ & $-0.4^{\star * \star}$ & $-2.5^{\star \star \star}$ & -0.1 & $-2.7^{\star \star \star *}$ & $-2.0^{\star}$ & -1.6 & -0.1 \\
\hline & $(0.0)$ & $(0.1)$ & $(0.1)$ & $(0.8)$ & (0.1) & $(1.0)$ & $(1.2)$ & (1.2) & (0.1) \\
\hline \multirow[t]{2}{*}{+3} & $-0.1^{\star \star \star}$ & $-0.2^{\star}$ & $-0.4^{\star \star}$ & $-1.1^{\star *}$ & -0.1 & -0.8 & -0.1 & 0.3 & $0.2^{* \star}$ \\
\hline & $(0.0)$ & $(0.1)$ & $(0.1)$ & $(0.5)$ & $(0.2)$ & $(0.8)$ & $(1.8)$ & (1.9) & $(0.1)$ \\
\hline
\end{tabular}

B. Firms w/ CEO Turnover only in $[-1,+1]$

\begin{tabular}{c|cllllllll} 
Period & Salary & Bonus & TCC & BLKV & RSTGRNT & TDC1 & EXER & TDC2 & OPGRNT \\
\hline $\mathbf{- 2}$ & 0.0 & $-0.2^{\star \star \star}$ & $-0.2^{\star \star \star}$ & -0.9 & 0.0 & -1.3 & -0.1 & -0.3 & 0.0 \\
& $(0.0)$ & $(0.0)$ & $(0.1)$ & $(0.8)$ & $(0.1)$ & $(0.8)$ & $(0.7)$ & $(0.7)$ & $(0.1)$ \\
$\mathbf{- 1}$ & 0.0 & $-0.2^{\star \star \star}$ & $-0.2^{\star}$ & $5.1^{\star \star \star}$ & 0.0 & $4.9^{\star}$ & -0.2 & -0.3 & 0.1 \\
& $(0.0)$ & $(0.1)$ & $(0.1)$ & $(2.0)$ & $(0.1)$ & $(2.8)$ & $(0.4)$ & $(0.6)$ & $(0.1)$ \\
\hline $\mathbf{0}$ & $-0.1^{\star \star}$ & $-0.3^{\star \star \star}$ & $-0.4^{\star \star \star}$ & $-1.0^{\star \star}$ & 0.0 & $-1.5^{\star \star}$ & -0.1 & -0.7 & $0.3^{\star \star \star}$ \\
& $(0.0)$ & $(0.1)$ & $(0.1)$ & $(0.5)$ & $(0.1)$ & $(0.6)$ & $(0.6)$ & $(0.6)$ & $(0.1)$ \\
\hline$+\mathbf{+ 1}$ & 0.0 & -0.1 & -0.1 & $-2.6^{\star \star \star}$ & -0.2 & $-2.9^{\star \star \star}$ & 0.2 & 0.1 & -0.1 \\
& $(0.0)$ & $(0.1)$ & $(0.1)$ & $(1.0)$ & $(0.2)$ & $(1.1)$ & $(0.8)$ & $(0.8)$ & $(0.1)$ \\
$+\mathbf{+ 2}$ & 0.0 & $-0.2^{\star}$ & $-0.2^{\star \star}$ & $-1.7^{\star \star \star}$ & 0.1 & $-1.2^{\star \star}$ & 0.3 & 0.4 & 0.0 \\
& $(0.0)$ & $(0.1)$ & $(0.1)$ & $(0.6)$ & $(0.1)$ & $(0.5)$ & $(0.7)$ & $(0.8)$ & $(0.1)$ \\
$+\mathbf{+ 3}$ & 0.0 & -0.2 & -0.2 & $-1.5^{\star \star}$ & 0.1 & $-2.3^{\star \star *}$ & -0.7 & -1.2 & $-0.1^{*}$ \\
& $(0.0)$ & $(0.1)$ & $(0.1)$ & $(0.6)$ & $(0.1)$ & $(0.6)$ & $(0.7)$ & $(0.8)$ & $(0.1)$
\end{tabular}

Notes:

Robust standard errors in parentheses

* significant at $10 \%$; ${ }^{* \star}$ significant at $5 \%{ }^{*}$; *** significant at $1 \%$

All variables are expressed in \$ millions, except for OPGRNT

TCC = Total Current Compensation (Salary + Bonus)

BLKV = Black-Scholes Value of Option Grants

RSTGRNT = Restricted Stock Grants Value

TDC1 = Total Direct Compensation 1 (TCC + BLKV + RSTGRNT + Others)

EXER = Value Realized from Option Exercises

TDC2 = Total Direct Compensation 2 (TCC + EXER + RSTGRNT + Others)

OPGRNT = Log(Option Shares Granted / Total Shares Outstanding) 
Table 8. Descriptive statistics for proportions of lucky grants: Before and after SOX

$\%$ of lucky grants (options granted with the grant prices below or at the lowest price within the grant month)

\begin{tabular}{|c|c|c|c|c|c|c|c|c|c|c|c|c|}
\hline \multirow{3}{*}{ Period } & \multicolumn{6}{|c|}{ Raw } & \multicolumn{6}{|c|}{ Net (Controlling for number of trading days) } \\
\hline & \multicolumn{3}{|c|}{ Treated } & \multicolumn{3}{|c|}{ Potential Controls } & \multicolumn{3}{|c|}{ Treated } & \multicolumn{3}{|c|}{ Potential Controls } \\
\hline & Mean & S.D. & $\mathbf{N}$ & Mean & S.D. & $\mathbf{N}$ & Mean & S.D. & $\mathbf{N}$ & Mean & S.D. & $\mathbf{N}$ \\
\hline & \multicolumn{6}{|c|}{ Before SOX } & \multicolumn{6}{|c|}{ Before SOX } \\
\hline-3 & 15.1 & 34.8 & 99 & 13.6 & 33.5 & 1,205 & 11.0 & 34.5 & 99 & 9.3 & 32.7 & 1,195 \\
\hline-2 & 19.0 & 37.6 & 99 & 14.3 & 34.1 & 1,200 & 14.4 & 37.1 & 99 & 10.1 & 33.7 & 1,200 \\
\hline-1 & 9.2 & 28.0 & 99 & 12.5 & 32.0 & 1,200 & 4.8 & 27.5 & 99 & 8.3 & 31.4 & 1,198 \\
\hline 0 & 7.9 & 26.6 & 94 & 11.5 & 30.8 & 1,174 & 3.5 & 25.7 & 94 & 7.2 & 30.4 & 1,174 \\
\hline+1 & 9.4 & 28.2 & 80 & 11.8 & 31.4 & 1,012 & 4.2 & 29.0 & 80 & 7.5 & 31.0 & 1,012 \\
\hline+2 & 10.4 & 28.9 & 62 & 11.3 & 30.4 & 688 & 5.7 & 26.9 & 62 & 7.1 & 30.1 & 688 \\
\hline \multirow[t]{2}{*}{+3} & 5.2 & 21.1 & 52 & 12.4 & 32.0 & 494 & 0.9 & 20.9 & 52 & 8.2 & 31.6 & 494 \\
\hline & \multicolumn{6}{|c|}{ After SOX } & \multicolumn{6}{|c|}{ After SOX } \\
\hline+2 & 2.9 & 16.9 & 35 & 4.7 & 20.6 & 521 & -0.5 & 16.8 & 35 & 0.9 & 20.5 & 521 \\
\hline+3 & 7.4 & 24.1 & 41 & 8.5 & 27.3 & 586 & 3.6 & 24.0 & 41 & 5.1 & 26.8 & 586 \\
\hline
\end{tabular}


Table 9. Average Treatment Effect for the Treated (ATT) of financial distress Proportions of lucky grants (only for grants before passage of SOX) Bias-Corrected Matching Estimator

A. Variables in Levels

\begin{tabular}{c|cc}
\multicolumn{3}{c}{ \% of lucky grants } \\
\hline Period & Raw & Net \\
\hline $\mathbf{- 2}$ & 1.6 & 1.3 \\
& $(4.3)$ & $(4.3)$ \\
$\mathbf{- 1}$ & -5.5 & -5.7 \\
& $(3.8)$ & $(3.6)$ \\
\hline $\mathbf{0}$ & $-6.5^{\star}$ & $-7.2^{\star \star}$ \\
& $(3.3)$ & $(3.1)$ \\
\hline $\mathbf{+ 1}$ & $-8.7^{\star \star}$ & $-8.9^{\star \star}$ \\
& $(4.0)$ & $(3.8)$ \\
$\mathbf{+ 2}$ & -4.5 & -4.6 \\
& $(3.9)$ & $(3.6)$ \\
$\mathbf{+ 3}$ & -4.4 & -5.9 \\
& $(4.3)$ & $(4.4)$
\end{tabular}

B. Variables in differences with respect to their values in period -3

$\%$ of lucky grants

\begin{tabular}{c|cc}
\hline Period & Raw & Net \\
\hline $\mathbf{- 2}$ & 8.3 & 6.0 \\
& $(5.7)$ & $(5.6)$ \\
$\mathbf{- 1}$ & -0.3 & -0.8 \\
& $(5.6)$ & $(5.5)$ \\
\hline $\mathbf{0}$ & -2.9 & -3.5 \\
& $(5.2)$ & $(5.3)$ \\
\hline $\mathbf{+ 1}$ & -3.5 & -5.1 \\
& $(6.0)$ & $(5.8)$ \\
$\mathbf{+ 2}$ & 2.6 & 2.2 \\
& $(5.5)$ & $(5.2)$ \\
$\mathbf{+ 3}$ & -5.2 & -6.7 \\
& $(6.4)$ & $(6.4)$
\end{tabular}

Notes:

Robust standard errors in parentheses

* significant at $10 \%$; ** significant at $5 \%$; *** significant at $1 \%$ 